\title{
Air Transport versus High-Speed Rail: An Overview and Research Agenda
}

\author{
Xiaoqian Sun, ${ }^{1,2}$ Yu Zhang, ${ }^{3}$ and Sebastian Wandelt ${ }^{1,2}$ \\ ${ }^{1}$ School of Electronic and Information Engineering, Beihang University, Beijing 100191, China \\ ${ }^{2}$ Beijing Key Laboratory for Network-Based Cooperative ATM, Beijing 100191, China \\ ${ }^{3}$ Department of Civil and Environmental Engineering, University of South Florida, Tampa, FL 33620, USA
}

Correspondence should be addressed to Sebastian Wandelt; wandelt@informatik.hu-berlin.de

Received 8 November 2016; Revised 23 March 2017; Accepted 6 April 2017; Published 25 May 2017

Academic Editor: Chien-Hung Wei

Copyright (C) 2017 Xiaoqian Sun et al. This is an open access article distributed under the Creative Commons Attribution License, which permits unrestricted use, distribution, and reproduction in any medium, provided the original work is properly cited.

\begin{abstract}
The development of high-speed rail (HSR) services throughout the last decades has gradually blurred the concept of competition and cooperation with air transportation. There is a wide range of studies on this subject, with a particular focus on single lines or smaller regions. This article synthesizes and discusses recently published studies in this area, while aiming to identify commonalities and deviations among different regions throughout the world, covering services from Europe, Asia, and North America. Our meta-analysis reveals that the literature is highly controversial and the results vary substantially from one region to another, and a generalization is difficult, given route-specific characteristics, such as demand distribution, network structure, and evolution of transportation modes. As a major contribution, we propose a list of five challenges as a future research agenda on HSR/air transport competition and cooperation. Among others, we see a need for the construction of an open-source dataset for large-scale multimodal transport systems, the comprehensive assessment of new emerging transport modes, and also taking into account the resilience of multimodal transport systems under disruption.
\end{abstract}

\section{Introduction}

After long-lasting successes in Japan (Shinkansen), France (TGV), and Germany (ICE), HSR has seen further success stories in countries like China, Italy, Spain, and Korea; several routes are under discussion in United States and United Kingdom. While it is costly to plan, construct, operate, and maintain a HSR system, with billions of dollars, HSR has significant impacts on mobility patterns $[1,2]$, economic development $[3,4]$, energy consumption $[5,6]$, land use of a country [7], and overall service quality [8]. Moreover, an often advertised effect of HSR is that it will be a key technology for greener transportation and railway stations are usually built closer to city centers than airports, which gives the HSR a travel time advantage over other transportation modes between $200 \mathrm{~km}$ and 1,000 km [9]. In Figure 1, we highlight an example for traveling between Beijing and Shanghai in China. The travel time for both modes is almost identical, while the (ground) distance is more than $1,200 \mathrm{~km}$. Accordingly, many passengers take the HSR for trips between
Beijing and Shanghai, given that (a) the ticket price for HSR is roughly one-third of the air fare and (b) the level of comfort (e.g., as measured by available space) is slightly higher. This shows that the competition range between HSR and air transportation has increased significantly over the years. Naturally, this is a rather specific example for China's recent high-speed railway success story and cannot be transferred directly to other regions, as we discuss below.

The competition and cooperation between air transport and HSR in Europe and Asia have been extensively explored, based on many case studies of single routes or smaller regions. However, the results in these studies do not necessarily hold cross-regional transfers $[10,11]$ : since the competition and cooperation patterns between air transport and HSR are dissimilar in different markets, it is necessary to have a global overview on the developments in different regions based on cross-comparison of air transport and HSR [12]. In particular, the route structure of the HSR network in a region has substantial impacts on the passenger demand and revenues; and transferring results from one topology to another is 


\begin{tabular}{|c|c|c|}
\hline Time & Location & Mode \\
\hline 08:20 & Beijing Capital Times Square & \multirow{2}{*}{ Walk } \\
\hline 08:30 & Xidan & \\
\hline 08:40 & l & \multirow{3}{*}{ Metro Line 4} \\
\hline 08:50 & | & \\
\hline 09:00 & Xuanwumen & \\
\hline 09:10 & 1 & \multirow{3}{*}{ Metro Line 2} \\
\hline 09:30 & | & \\
\hline 09:40 & Dongzhimen & \\
\hline 09:50 & I & \multirow{2}{*}{ Metro Airport Lin } \\
\hline 10:00 & Beijing Capital International Airport & \\
\hline \multicolumn{3}{|l|}{ 10:10 } \\
\hline$\cdots$ & $\cdots$ & \\
\hline \multicolumn{3}{|l|}{$11: 20$} \\
\hline $11: 30$ & Beijing Capital International Airport & \\
\hline 11:40 & | & $\rightarrow$ \\
\hline 11:50 & | & - \\
\hline$\cdots$ & $\cdots$ & Air China 1557 \\
\hline 13:20 & | & $\mu$ \\
\hline 13:30 & | & \\
\hline 13:40 & Shanghai Hongqiao & \\
\hline $13: 50$ & Pick-up luggage & \\
\hline
\end{tabular}

(a) Travel mode: metro + aircraft

\begin{tabular}{|c|c|c|}
\hline Time & Location & Mode \\
\hline 08:20 & Beijing Capital Times Square & \multirow{2}{*}{ Walk } \\
\hline 08:30 & Xidan & \\
\hline 08:40 & Beijing South Railway Station & Metro Line 4 \\
\hline \multicolumn{3}{|l|}{ 08:50 } \\
\hline 09:00 & Beijing South Railway Station & \\
\hline 09:10 & 1 & \\
\hline 09:20 & | & \\
\hline 09:30 & | & \\
\hline 09:40 & | & \\
\hline 09:50 & | & \\
\hline 10:00 & | & \\
\hline$\cdots$ & $\cdots$ & \\
\hline $11: 20$ & | & High-speed rail G1 \\
\hline $11: 30$ & | & \\
\hline 11:40 & | & \\
\hline 11:50 & | & \\
\hline $13: 10$ & | & \\
\hline $13: 20$ & | & \\
\hline $13: 30$ & | & \\
\hline 13:40 & | & \\
\hline 13:50 & Shanghai Hongqiao & \\
\hline
\end{tabular}

(b) Travel mode: metro + high-speed rail

FIGURE 1: Comparison of air transportation and high-speed rail for a trip from Beijing Capital Times Square to Shanghai Hongqiao in China. Despite the large spatial distance of more than $1,200 \mathrm{~km}$, passengers using either mode arrive approximately at the same time in Shanghai. This example highlights the substantially different competition range between both modes, compared to the standard values for other regions around the world (often $200-300 \mathrm{~km}$ ).

often difficult [13-15]. As noted in [16], infrastructure costs in United Kingdom are particularly high and a major hurdle for HSR realization. In China, on the other hand, HSR construction costs are rather low, especially due to lower labour costs, high-volume projects with smaller amortized costs, and cheaper tunnel construction [17]. Different costs significantly affect the profitability of HSR and the competitiveness against air transport.

The first goal of this study is to provide a synthesis on the differences and similarities of the competition and cooperation effects between air transport and HSR across different regions. In recent years, much progress has been made in this research area. Therefore, in this paper, we provide a review up to 2016 on the competition and cooperation between air transport and HSR. Our study is based on ten countries, many of which are key players in high-speed rail in the last years: five countries from Europe (Spain, France, Germany, United Kingdom, and Italy), three countries from Asia (China, Japan, and South Korea), and two from North America (Canada and United States). We synthesize and discuss recently published studies regarding these ten countries, with a particular focus on (a) passenger demand, (b) travel time, (c) ticket price, (d) seats/frequencies, and (e) environment and social welfare. For many evaluation factors, we show that the existing literature is highly controversial, while it seems to be globally agreed that travel time and high passenger demand are the key drivers for the success of a HSR system. Moreover, the structure of the network and distribution of population along a line are critical factors for profitability of HSR lines in competition to air carriers. For the cooperation, on the other hand, connection time between modes is critical for the success.

As a second contribution, we propose a list of five main challenges as a future research agenda on HSR/air transport competition and cooperation. Our list mainly aims to inspire researchers rather than provide a complete list, although practitioners and policy makers could also benefit. Among others, we see a need for the construction of an open-source dataset for large-scale multimodal transport systems, which will allow researchers to perform wider comprehensive and comparable studies on the effects of competition and cooperation. Current studies are strongly biased by the availability of data for a few regions, for example, in Spain. Furthermore, a comprehensive assessment of new emerging transport modes, such as coaches and overnight HSR trains, taking into account the resilience of multimodal transport systems under disruption, is necessary as well.

The remainder of this paper is organized as follows. Section 2 provides an overview of air transport networks and HSR networks in Europe, Asia, and North America, together with the competition and cooperation effects between air 
TABLE 1: Overview of the domestic air transport in five countries in Europe, three countries in Asia, and two countries in North America for the year 2015. Note that the busiest airport is ranked according to the number of domestic passengers. Data source: Sabre Airline Solutions (https://www.sabreairlinesolutions.com/). The abbreviation LF stands for load factor.

\begin{tabular}{|c|c|c|c|c|c|c|c|}
\hline Continents & Country & Airport & Busiest airport & Avg. LF & Yield (Cent/km) & Departures & Total passengers \\
\hline \multirow{5}{*}{ Europe } & ES & 45 & MAD & $81.63 \%$ & 11.26 & 303,834 & $30,851,832$ \\
\hline & FR & 73 & ORY & $79.15 \%$ & 20.10 & 52,433 & $23,978,266$ \\
\hline & $\mathrm{DE}$ & 35 & MUC & $73.97 \%$ & 18.79 & 235,986 & $24,601,384$ \\
\hline & UK & 40 & LHR & $76.24 \%$ & 23.47 & 308,476 & $22,613,459$ \\
\hline & IT & 41 & FCO & $80.20 \%$ & 9.16 & 242,029 & $29,057,702$ \\
\hline \multirow{3}{*}{ Asia } & $\mathrm{CN}$ & 152 & PEK & $83.09 \%$ & 14.38 & $3,160,887$ & $415,336,119$ \\
\hline & $\mathrm{JP}$ & 72 & HND & $77.51 \%$ & 18.01 & 814,697 & $109,489,933$ \\
\hline & $\mathrm{KR}$ & 15 & CJU & $82.44 \%$ & 17.70 & 145,738 & $22,839,327$ \\
\hline \multirow{2}{*}{ North America } & $\mathrm{CA}$ & 257 & YYZ & $80.20 \%$ & 12.79 & 796,976 & $46,253,333$ \\
\hline & US & 781 & ATL & $84.72 \%$ & 10.26 & $7,925,761$ & $697,090,531$ \\
\hline
\end{tabular}

TABLE 2: Overview of the HSR in five countries in Europe, three countries in Asia, and two countries in North America. Note that we use the latest data which is available. Data source: collected by hand from public accessible web pages.

\begin{tabular}{lcccccc}
\hline Continents & Country & Stations & Length $(\mathrm{km})$ & Busiest route & Busiest station & Total passengers (year) \\
\hline \multirow{4}{*}{ Europe } & ES & 30 & 3,100 & Madrid-Barcelona & Madrid Atocha & $14,900,000(2013)$ \\
& FR & 172 & 2,037 & Paris-London/Lille & Paris Gare du & $114,450,000(2010)$ \\
& DE & 180 & 2,635 & Frankfurt-Hannover & Frankfurt & $77,200,000(2009)$ \\
& UK & 4 & 108 & High Speed 1 & London St Pancras & Not Available Yet \\
\multirow{3}{*}{ Asia } & IT & 23 & 926 & Milan-Rome & Rome Termini & $38,900,000(2013)$ \\
& CN & 514 & 19,449 & Beijing-Shanghai & Shanghai Hongqiao & $910,000,000(2015)$ \\
& JP & 104 & 2,765 & Tokaido-Shinkansen & Tokyo & $324,442,000(2010)$ \\
\multirow{2}{*}{ North America } & KR & 45 & 420 & Gyeongbu-Gosokseon & Seoul & $54,068,370(2014)$ \\
& CA & None & None & None & None & None \\
& US & 16 & 734 & Northeast Corridor & Pennsylvania & $3,343,143(2013)$ \\
\hline
\end{tabular}

transport and HSR. Discussions and a list of future research directions are provided in Section 3.

\section{HSR and Air Transport Networks in Europe, Asia, and North America}

There is a rich body of literature on HSR versus air transportation, with a focus on single lines or smaller regions. Generalizing results from one region to another is difficult, given route-specific characteristics, such as demand distribution, network structure, and evolution of transportation modes.

2.1. A Survey on High-Speed Railway versus Air Transportation. Table 1 provides an overview of the domestic air transport in these countries for the year 2015. We can observe that United States has the maximum number of airports, among which ATL (Hartsfield-Jackson Atlanta International Airport) is the busiest domestic airport in the world, followed by PEK (Beijing Capital International Airport) in China and HND (Haneda Airport) in Japan. It is interesting to note that the yield in Italy is the lowest (i.e., the airlines are probably least profitable) among the ten countries, while United Kingdom has the highest yield (i.e., the airlines are very likely to be more profitable). Table 2 , on the other hand, provides an overview over the domestic HSR networks in all countries. China has the largest network, regarding the total length and also the number of stations. The busiest station in China is Shanghai Hongqiao, at the same time the largest railway station in Asia. China is also the country with the highest number of passengers per year, followed by Japan. For an overview, see $[56,57]$. The air transportation networks in different regions often share highly similar topological properties $[58,59]$.

In general, HSR lines can be categorized into four distinct types, depending on how the infrastructure is shared [18]; see Figure 2. In the exclusive exploitation model, high-speed rails and conventional rails have a clear separation and both of them have their own infrastructure. In the mixed highspeed model, HSR can run on specially built lines and upgraded conventional lines. Conventional rails can run on both infrastructures in the mixed conventional model. Both HSR and conventional rails can run on both infrastructures in the fully mixed model.

Figure 3(a) shows the HSR networks in the five European countries (Spain, France, Germany, United Kingdom, and Italy), while Figure 3(b) shows their domestic air transport networks. Note that only domestic flights with more than 1,000 passengers per month and with distances less than $1,000 \mathrm{~km}$ are shown. We set the distance threshold as $1,000 \mathrm{~km}$ since HSR is most competitive against air transport for routes less than $1,000 \mathrm{~km}[60]$. We can observe that highly developed air transport networks are still denser than newly emerged 
(1) Exclusive exploitation

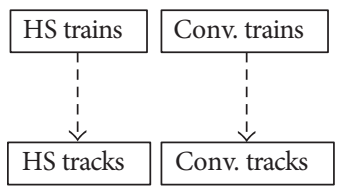

(2) Mixed HS

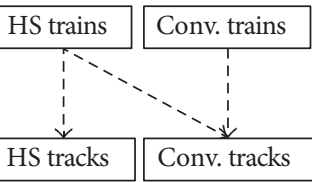

(3) Mixed Conv.

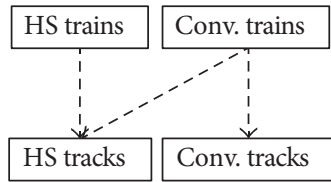

(4) Fully mixed

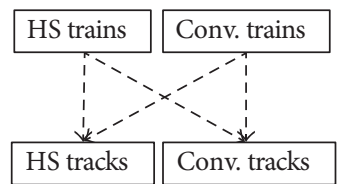

FIGURE 2: Four types of HSR models adapted from [18], where HS represents high-speed and Conv. represents conventional.

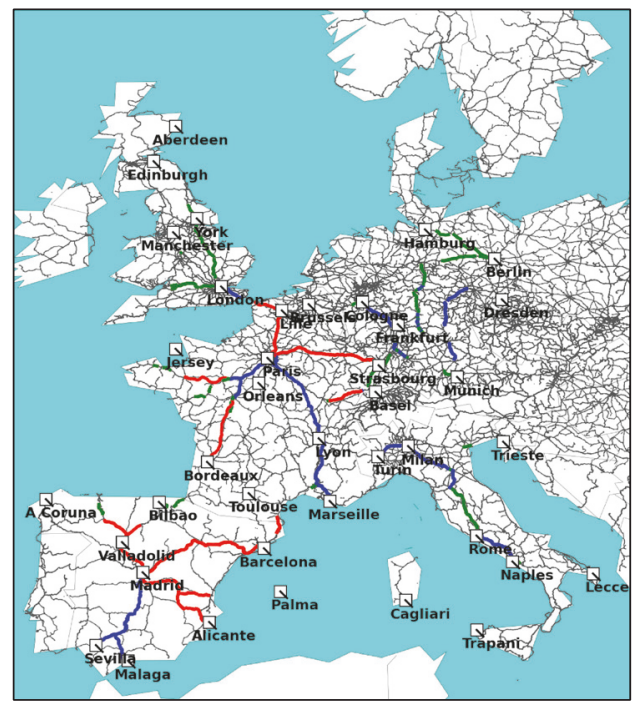

(a) HSR network (data source: OpenStreetMap)

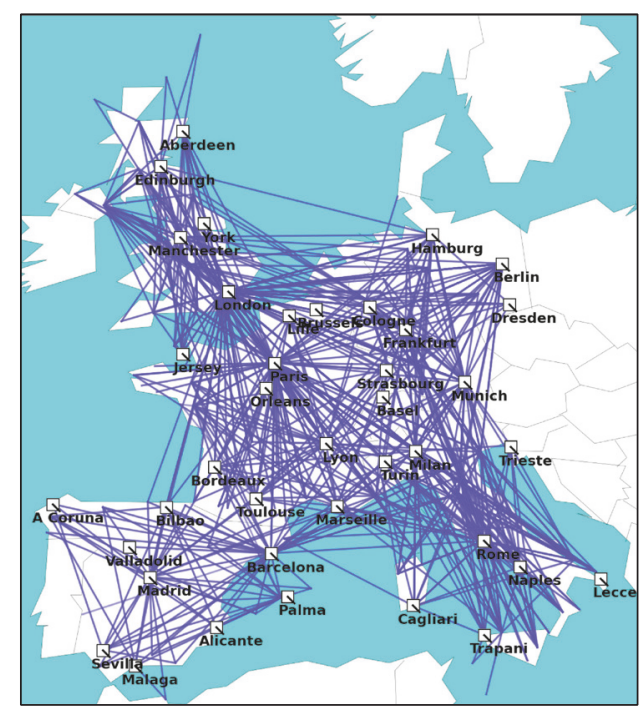

(b) Airport network (data source: Sabre Airline Solutions)

FIGURE 3: Comparison of HSR networks and airport networks in five European countries (Spain, France, Germany, United Kingdom, and Italy). In the HSR networks, different colors indicate different maximum speed: green color $>200 \mathrm{~km} / \mathrm{h}$; blue color $>250 \mathrm{~km} / \mathrm{h}$; red color $>$ $300 \mathrm{~km} / \mathrm{h}$. In the airport networks, domestic flights with passengers more than 1,000 per month and with distances less than 1,000 km are shown. It can be seen that highly developed air transport networks are still denser than newly emerged HSR networks.

HSR networks. Below, we briefly summarize HSR and air transport networks in all five European countries. The Alta Velocidad Española (AVE) in Spain is a mixed conventional model, with a comprehensive network of more than $3,100 \mathrm{~km}$. The country disposes approx. 45 passenger airports. The busy route between Madrid and Barcelona [61] is a recurring subject of research for the competition of HSR with airlines. We believe that a major reason is that HSR operator Renfe makes many datasets available for public use. The French Train à Grande Vitesse (TGV) belongs to the category of mixed high-speed model and is a hybrid network of more than $2,030 \mathrm{~km}$. France has around 70 passenger airports. As of 2015, the majority of the network is highly unprofitable and the number of stations has to be significantly reduced, in order to make the network more attractive [62]. The German Intercity Express (ICE) falls into the category of full mixed model and is best described as a hybrid network. The overall length of the network is estimated with $2,635 \mathrm{~km}$. The German airport network consists of a core with about 35 active passenger airports. The HSR network of United Kingdom is best described as a hybrid network. The airport network in United Kingdom consists of around 40 airports with regular passenger traffic. The Italian HSR (operated by Trenitalia and NTV) belongs to the category of full mixed model and is best described as a corridor. The HSR network mainly consists of one line from Turin to Naples, of approx. $900 \mathrm{~km}$ length. The airport network in Italy consists of around 40 airports with regular passenger traffic.

Figure 4(a) shows the HSR networks in the three Asian countries: China, Japan, and Korea, while Figure 4(b) shows domestic airport networks. Note that only domestic flights with passengers more than 1,000 per month and with distances less than $1,000 \mathrm{~km}$ are shown. We set the distance threshold as $1,000 \mathrm{~km}$ since HSR is most competitive against air transport for routes less than $1,000 \mathrm{~km}$ [60]. Similar with European cases, highly developed air transport networks are much denser than newly emerged HSR networks in the three Asian countries. Below, we briefly summarize HSR and air transport networks in all three Asian countries. The Chinese HSR network is the largest worldwide and best categorized as mixed usage and hybrid network. Following its fast spreading during the recent years, the network consists of tracks summing up to over $19,000 \mathrm{~km}$. Regarding the passenger usage per year, China is ranked number one in the world [63]. Almost one billion passengers have traveled with HSR transportation in the year 2014. The airport network of China consists of 193 airports with more than 1500 passengers per month in the year 2015. The Shinkansen in Japan belongs 


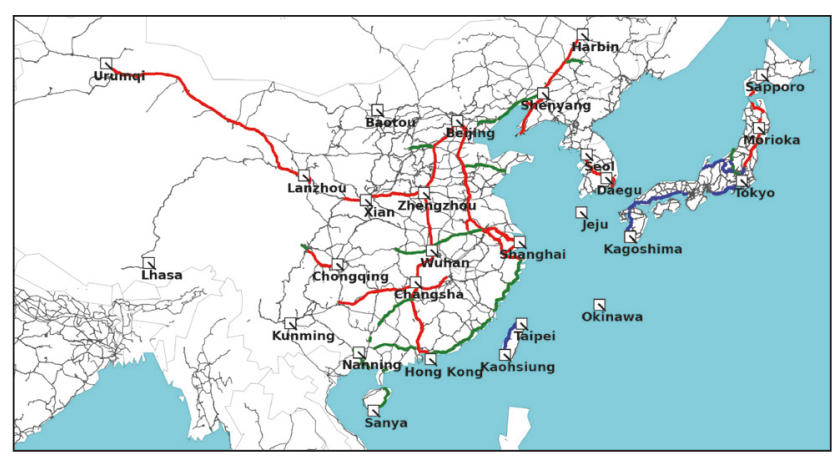

(a) HSR network (data source: OpenStreetMap)

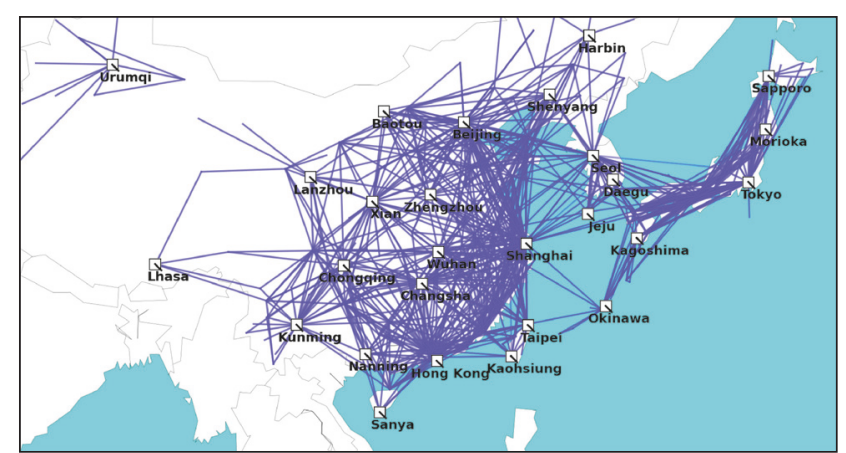

(b) Airport network (data source: Sabre Airline Solutions)

FIGURE 4: Comparison of HSR networks and airport networks in three Asian countries (China, Japan, and Korea). In the HSR networks, different colors indicate different maximum speed: green color $>200 \mathrm{~km} / \mathrm{h}$; blue color $>250 \mathrm{~km} / \mathrm{h}$; red color $>300 \mathrm{~km} / \mathrm{h}$. In the airport networks, domestic flights with passengers more than 1,000 per month and with distances less than 1,000 km are shown. Similar with the situations in Europe, highly developed air transport networks are much denser than newly emerged HSR networks.

to the category of exclusive exploitation model and is best described as a corridor. Originally opened in 1964, on time with the Summer Olympics in Tokyo, the success of Japanese HSR networks started with the Tokaido Shinkansen [64]. Currently, the networks consist of $2,765 \mathrm{~km}$ HSR railways, linking most major cities on the islands of Honshu and Kyushu. Japan has around 70 airports with regular passenger traffic, distributed among its islands. The South Korea Train eXpress (KTX) was opened in 2004 and best described as an exclusive corridor. The network mainly consists of one line from Incheon International Airport, to Daegu/Busan, passing by Seoul. The track is around $350 \mathrm{~km}$ long. South Korea has 15 airports with regularly scheduled passenger service. The domestic transportation in South Korea is very special, given the extraordinary air travel demand from Seoul to Jeju, but no alternatives for transportation [65]. Therefore, it is interesting to note that the KTX network outranked the Korean air travel, regarding the number of passengers, already two years after its inauguration [18].

Canada does not have any high-speed railway. Although there had been plans for HSR in United States since 1960s [66], there is only one HSR service in operation: Acela Express in Northeast corridor between Washington and Boston, with 14 intermediate stops including Philadelphia and New York. The North American airport network is one of the largest in the world: approximately half of the worldwide air traffic takes place in this region. Moreover, 12 of the top 30 busiest airports in the world are located in the United States. The biggest airport is Atlanta, with almost 100 million passengers per year.

Full Service Airlines versus Low-Cost Carriers. Studies in the airline industry have empirically identified significant product differentiation and cost differences between full service airlines and low-cost carriers (LCCs). Although earlier studies are mostly for Europe and US, some recent studies have been carried out for Asian markets including China, which is a major HSR market. Hereby we briefly review the key differences between full service airlines and LCCs and also how they affect the competition/cooperation between air and HSR.
There are significant differences between full service airlines and LCCs: while full service airlines are often characterized by hub-and-spoke network structures, large route networks, large fleet size with multiple types of aircraft, and differentiated products serving heterogeneous passengers, including short-medium-long haul flights, LCCs generally have point-to-point network structures, low operating costs, and decreased ticket prices and are less comfort, with focus on short and medium haul flights. With continued growth, LCCs are expanding their operations at major airports/cities as well and this triggers more direct competition between full service airlines and LCCs. While LCCs are quite popular in Europe and US, there are still a few LCCs in China; their domestic market is less than 3\% [67].

Based on the 2012 data and the controlling for travel time, Dobruszkes et al. showed that the European LCCs do not compete with HSR services [11]. However, the expansion of LCCs to major airports/cities might involve tougher competition with HSR, since one of the major advantages of HSR is to transport passengers from one city center to another [68]. With different market focus, that is, LCC for short or medium haul flight passengers only, cooperation between full service airlines and LCCs might also trigger more competition for HSR customers. This cooperation model is especially attracting for passengers with connecting flights, for instance, all-pass luggage transfer and security check. We believe that air-rail cooperation would contribute towards the ultimate goal of transporting passengers or goods from their origins to destinations safely, efficiently, and environmentally friendly.

\subsection{Competition and Cooperation Effects between Air Trans-} port and HSR Networks. This section provides an overview on the competition and cooperation effects between air transport and HSR networks as reported in the literature. The overall goal of this section is to collect evidence for commonalities and deviations among study results.

Different methodologies and models have been used in the literature, such as stated preference versus revealed preference and empirical estimation versus simulation. Stated preference (SP) and revealed preference (RP) are different 
ways to collect information on the preferences of consumers [69]. Although the data obtained from SP and RP is not always consistent, it is believed that SP is more useful when evaluating hypothetical choice alternatives, while RP is more appropriate for existing ones [70]. Empirical estimation is mainly based on the available data, experience, and knowledge, which are collected from the past, in order to obtain some findings [25], while simulation often requires to develop a model first, representing key characteristics, behaviors, and functions of the selected real-world process or system [71]. Note that the differences in conclusions may be partly ascribed to different methodologies and models used.

We list the major findings of research studies according to the following eight main categories: passenger demand, travel time, price, seats and frequencies, environment and social welfare, value of time, elasticity/cross-elasticity, and cost ranges. For each category, we synthesize major findings for the ten countries. This section lays the foundation for our discussion on future research in this area; see Section 3.

Effects on Passenger Demand. As a new transport mode, the entry of HSR into the medium- and long-distance markets triggers strong competitions with air transport. In addition to self-induced passenger demand, HSR also directly attracts significant numbers of passengers from other transport modes. Table 5 provides an overview of the competition and cooperation effects on passenger demand, including the region and time frame under study, the competition and/or cooperation effects covered, whether the data is real-world or not, and what main results are obtained. In general, it seems to be agreed that, after the entry of HSR, the short haul market share of air transport has declined and there are modal dynamics that passengers are shifting from air transport to HSR. Significant airfare reduction could regain demands back to air transport, particularly air transport operated by low-cost carriers. In addition, HSR is able to generate passenger demands by itself. On the other hand, some analysis showed that HSR has influenced passenger demand less than expected (France) or only for local regions (Paris). Moreover, mature HSR networks may face a period of reduced demand growth, after an initial phase of excitement (Japan).

Effects on Travel Time. Travel time is critical for the competitiveness of different transport modes. An overview of the competition and cooperation effects on travel time is provided in Table 6. It can be seen that passengers tend to select HSR if the travel time is shorter than air transport; these are travelers' behaviors in most European countries. In Japan, travel time is one of the most sensitive factors for passengers' choice behavior, while price is modestly sensitive. In China, HSR is rather competitive regarding total travel time in shortmedium haul market. The cooperation between HSR and air transport in the case of London Heathrow airport shows large potentials in reducing total travel time for the passengers. An important, yet often ignored, contribution to travel time is the connection time between air transport/HSR, which makes schedule coordination crucial for successful intermodality.
Effects on Price. It is also interesting to check how the competition and cooperation between HSR and air transport influence the ticket prices. Table 7 provides an overview of the competition and cooperation effects on price. Most existing research focused on the aspect of competition. It can be observed that airlines (Italy, Spain, and China) often take the reaction to reduce ticket prices under the HSR competition. On the other hand, passengers in Japan are less sensitive to the travel prices; thus reducing the prices of air tickets probably cannot attract more passengers. Taking into account the price differentiation between leisure passengers and business passengers is beneficial for the airlines. Furthermore, it is challenging to predict, whether a planned HSR project will be profitable or not. Direct transfers of obtained HSR experiences from Asia and Europe to new adopter countries (e.g., United States, Canada, and Australia) are problematic because of contextual differences. In general, constructions costs have a significant impact on the success of link-based HSR: the longer the distance, the higher the construction costs for lines, in contrast to node-based air transportation. For countries with low HSR construction and maintenance costs, for example, China, the probability of HSR being profitable is much higher than in countries with high construction costs, for example, United Kingdom and United States. Yet, there are some countries, for example, Japan and Korea, which have relatively high construction costs, but highly profitable HSR transportation. Notably, the HSR networks of these (island) countries are all best categorized as exclusive corridors. Construction and maintenance costs directly influence ticket prices and profitability.

Effects on Seats and Frequencies. Table 8 provides an overview of the competition and cooperation effects on the number of seats and flight frequencies. The reactions of airlines taken under the HSR competition are not clear: reducing the number of seats (aircraft size) is one common action. Whether the entry of HSR leads to the reduction of flight frequencies is not consistent in different regions across the world. It is highly controversial whether the flight frequencies were increased or decreased and it should be evaluated based on a consistent dataset in future studies.

Effects on Environment and Social Welfare. Table 9 provides an overview of the competition and cooperation effects on the environment and social welfare. Several studies focused on at least one of the following criteria: air pollutants, noise, land use, energy, and greenhouse gas emissions [72]; when compared with air transport, one major advantage of HSR is its environmental improvement, especially on $\mathrm{CO}_{2}$ emissions reduction. However, as shown by $[9,51,73]$, decreases in one pollutant may lead to increases in another.

Most studies look at the air-HSR in Europe. Based on an empirical comparison between air and HSR on the LondonParis route, [73] showed that there is no clear advantage to one mode over the other in terms of air pollution and it is in favor of HSR regarding climate change. Reference [50] constructed a model to assess the environmental impact of different transportation modes, with application to a new construction of a HSR station at Madrid Barajas airport. Results showed 
that, with HSR, passengers traveling with aircraft and private car are reduced, thus leading to environmental benefits. On the other hand, increasing the travel cost of private car is picked up by air transport rather than HSR, thus leading to negative environmental impacts. Reference [16] concluded that the overall benefits of HSR in UK are mainly induced by time savings and that the environmental and wider economic impacts of HSR are relatively small. Reference [74] showed that HSR is greener than air transport per seat-km (or passenger-km) from both operation and life-cycle analysis perspectives, when the load factor of HSR is high enough, but load factor of air transport is lower; the freed runway capacity is not reused. Moreover, the main advantage of HSR against air transport is travel time and the integrated airHSR could have larger environmental benefits. Reference [75] compared the environmental performance of HSR and air transport in European Union (EU) and it was shown that HSR has a better environmental performance than air transport and thus HSR should substitute air transport in order to mitigate environmental damage. Reference [53] investigated the environmental impact of $\mathrm{CO}_{2}$ emissions for air transport and rail, taking into account the infrastructure construction stage and the service provision stage. Analysis based on panel data showed that the operation of aviation industry is socially beneficial in the observed period (1999-2007), although its $\mathrm{CO}_{2}$ emission per passenger kilometer is higher than the one with rail. Reference [52] assessed several social and environmental effects when transforming a large airport into a multimodal transport node, where short haul flights would be substituted by HSR. With a theoretical model, [48] analyzed social welfare and environmental impacts due to the cooperation of air transport and HSR. The MadridMalaga route in Spain was used as an example to evaluate the proposed model. The results showed that, in both scenarios, there are gains from social and/or environmental aspects.

Although there is no HSR built in USA, yet there is a huge debate on the construction of HSR system, especially regarding environmental impacts. Reference [5] investigated the impact of HSR investments on interstate passenger transportation portfolio, fuel, and electricity consumption in USA, using a long-term investment planning model. The results showed that there are cases with significant HSR penetration; the national long-term $\mathrm{CO}_{2}$ emissions and costs could be decreased. Reference [46] showed that the greenhouse gas emissions could be reduced in USA with HSR. In general, people are more disturbed by aircraft noise than rail noise, which, according to [76], can be attributed to acoustic factors, as well as attitudes towards the noise source. Reference [51] evaluated future automobiles, HSR, and aircraft long-distance travel using the California corridor as a case study. It is shown that the environmental benefits are most sensitive to the number of automobile trips shifted to HSR; a HSR system with current technologies would provide significant environmental benefits over existing modes, when the ridership is high.

The Japanese air-HSR environmental aspects have been studied as well. Reference [25] empirically estimated passengers' preferences and choice behaviors using an air-rail demand model for Japanese domestic market. Results showed that $\mathrm{CO}_{2}$ emission taxation could reduce air passenger traffic and increase HSR passenger traffic in large numbers, although the relative change might be small.

It appears that the literature has not reached a consensus on the environmental and social welfare impacts of the integration between air transport and HSR. While some studies showed environmental benefits in Europe, other studies did not find a significant environmental impact (United Kingdom, Japan). Clearly, the measurement of environmental impact depends on several variables, and there is a need for a consistent way of cross-country impact assessments. Particularly, the spatial incompatibility between HSR and air transport makes the comparison of environmental assessments difficult [72]. More efforts are needed to understand the unintended trade-off in environmental impacts; that is, reduction in one environmental concern may lead to an increase or decrease in another.

Value of Time. Value of time (VoT) captures the travelers willingness to pay for the time savings and it is a fundamental concept in the transportation analysis tasks, such as travel demand modeling, social cost analysis, pricing decisions, and project evaluation [77-79]. Several studies have revealed that there are connections between the willingness to pay for time savings and several economic factors, such as time of a day, reliability preference, and activity scheduling; all of them revealed the heterogeneous VoT [77]. The most comprehensive study of UK values of time to date is provided in [80]. It was found that there is a high estimated elasticity of 0.9 between income and VoT; the ratio between walk/wait time and in-vehicle time is much lower than the commonly used value of two; there are several other important factors affecting the VoT, such as travel mode, travel purpose, and distance. Based on the idea that travelers often have different perceptions on the VoT, a varying VoT with a modal-mix model was proposed and the social profitability of three HSR lines Oslo-Stockholm (Norway and Sweden), Stockholm-Gothenburg (Sweden), and Beijing-Shanghai Hongqiao (China) was discussed [81]. Based on the Madrid-Barcelona corridor, it was shown that savings of waiting time are more valued than access time, while savings of access time are more valued than in-vehicle time [82].

Elasticity/Cross-Elasticity. Empirical studies confirmed that the time elasticity and price elasticity across different travel purposes are often different for segmented travelers. Based on the analysis of two main corridors in Spain (Madrid-Zaragoza and Madrid-Barcelona), [83] showed that the competition level that the HSR could exert over the air transport is low. The time elasticity of the HSR ranged from -0.36 to -0.59 , while its cost elasticity was -0.55 . Although the time and cost elasticities of HSR are quite diverse, a plausible range could be specified: time elasticity $(-0.8$ to -1.3$)$ and cost elasticity $(-0.5$ to -0.9$)$ [84]. Note that the above ranges did not consider the elasticities by travel purpose. The rail fare elasticities for rail (not limited to HSR) range between -0.27 and -0.61 when considering tours for long-distance 
travels in the UK [85]. It was also shown that there is a strong correlation between income and the frequency of longdistance travel trip making. For the Paris-Lyon HSR route in France which was opened with two stages between 1981 and 1983 , the in-vehicle travel time elasticity was around -1.6 in the first stage and then reduced to -1.1 after the opening of the Northern section [86]. The in-vehicle travel time elasticity for the Madrid-Barcelona route in Spain was around -1.3 [87]. It was observed that the absolute values of direct elasticity of HSR demand with regard to travel time are significantly greater than 1; there is an inverse relationship between the elasticity values and the distance from the Italian HSR market [88]. Based on time series data models, it was shown that the time and price elasticities on the number of trips are around -0.16 [89]. It was reported that generally the elasticities of long-distance models estimated on cross-sectional data in the literature tend to be lower than the elasticities observed when new HSR lines have been opened [90]. Based on quarterly route level panel data of air passenger demand from 2010 to 2013, the effects of HSR on China's big three airlines (Air China, China Eastern Airlines, and China Southern Airlines) were analyzed; it was found that the price elasticities of air traffic demand were -1.36 to -1.50 on all routes [91].

It was shown that elasticities are context dependent and they are influenced by regional socioeconomic differences, such as value of time, fuel prices, and GDP (Gross Domestic Product), as well as market segmentation (purpose of travel, distance classes, and transportation modes) [84]. Cautions are needed when interpreting the elasticities since they are usually estimated from small changes of the systems [92]. It was pointed out that cross-elasticities are less meaningful to compare between situations since they tend to highly depend on specific market conditions [90].

Cost Ranges. The operation costs of major European HSR networks have been reviewed in [18]: the cost ranged from 0.0776 Euro per seat kilometer for French TVG to 0.1766 Euro per seat kilometer for German ICE. Specifically, the construction cost for HSR in Spain is 7.8-20 million Euro per $\mathrm{km}$, and the maintenance cost is 33,457 Euro per $\mathrm{km}$. The construction cost for French HSR is 4.7-23 million Euro per $\mathrm{km}$, and the maintenance cost is 28,420 Euro per $\mathrm{km}$ (the values refer to the year 2002). The construction cost of the HSR network in Italy is 14-65.8 million Euro per km, and the maintenance cost is 12,919 Euro per $\mathrm{km}$ (the values refer to the year 2002). The construction cost of the HSR network in UK is around 66.2 million Euro per $\mathrm{km}$. Note that the values are referring to the year 2005, if they are not explicitly explained.

It was estimated that the long-term marginal cost for the Japanese Shinkansen ranges from 9.31 to 15.80 Yen per passenger kilometer [93]. Only limited studies analyzed the costs of a few HSR routes in China: it was reported that the minimum revenue per passenger kilometer for the BeijingTianjin route is $0.7 \mathrm{RMB}$ [94] and 0.76 RMB per passenger kilometer for Guangzhou-Wuhan route [12]. Although the cost estimations are quite different across markets, the cost of Chinese HSR is much lower than the ones for Japan and Europe [12].

\section{Discussions and Future Research Directions}

In the previous section, we surveyed recent literature on the competition and cooperation between air transport and HSR, covering five main categories: passenger demand, travel time, ticket price, seats and flight frequencies, and environment and social welfare. We summarize our main results as follows:

(1) It is shown that passengers are shifting from air transport to HSR and there is also newly induced demand generated by the HSR itself.

(2) Travel time is most critical in determining the competitiveness between the HSR and air transport: shorter travel time will attract more passengers.

(3) Under the HSR competition, airlines often reduce the ticket prices in order to keep passengers in European countries; the profitability of HSR is not easily predicted in different countries because of contextual differences.

(4) The reactions of airlines taken under the HSR competition are twofold: reducing the number of seats (aircraft size) is one common action, while flight frequencies being increased or decreased is highly controversial.

(5) There is no consensus on the impacts of environment and social welfare after the integration of air transport and HSR.

(6) The connections between the willingness to pay for time savings and several social-economic factors and the travelers' value of time are rather heterogeneous.

(7) Elasticities are often context dependent and they are influenced by regional social-economic differences (such as value of time, fuel prices); the interpretation of the elasticities needs more caution.

(8) Cost estimations across different markets show that the Chinese HSR is much cheaper than the Japanese HSR and European HSR.

Given these results, we discuss several lines of future research regarding intermodal transportation below and hope that more research efforts could be focused on these topics.

3.1. Creating an Open-Source Dataset for Large-Scale Multimodal Transport Systems. Research studies often use closedsource or hand-collected datasets. This makes it difficult to reproduce the results obtained in the study. Furthermore, this leads to inconsistent views on networks, being taken at different times, with different granularity and different observable variables [95]. Among European countries, the number of studies on the impacts of HSR in Spain ranks first. We believe that a major reason is that HSR operator Renfe makes many datasets available for public use. On the other hand, because of data confidential issues, only very limited research on the impact of HSR in Germany has been published. There is a strong need for an open access multimodal transportation database or, alternatively, largescale models for multimodal transportation. According to 
TABLE 3: An overview of the data sources for air transport.

\begin{tabular}{|c|c|c|}
\hline Region & Organizations & Links \\
\hline \multirow{6}{*}{ Global } & OAG (Official Airline Guide) & https://www.oag.com/ \\
\hline & ICAO (International Civil Aviation Organization) & http://www.icao.int \\
\hline & Airport Council International & http://www.airports.org \\
\hline & Sarbe Airport Data Intelligence & https://www.sabreairlinesolutions.com \\
\hline & Open Flights & http://openflights.org/ \\
\hline & Innovata Flight Schedules & http://www.innovata-llc.com \\
\hline \multirow{4}{*}{ China } & Transport scientific data sharing system & http://www.transdata.cn \\
\hline & Civil Aviation Administration of China & http://www.caac.gov.cn/ \\
\hline & The major Chinese online travel agency & http://www.ctrip.com \\
\hline & China Statistical Year Book & http://www.stats.gov.cn/english/ \\
\hline Japan & MLIT (Ministry of Land, Infrastructure, Transport and Tourism) & http://www.mlit.go.jp/index_e.html \\
\hline \multirow{2}{*}{ Spain } & Spanish Public Airport Authority & http://www.adif.es \\
\hline & AENA & http://www.aena.es \\
\hline France & Directorate General for Civil Aviation & http://www.aviation-civile.gouv.fr/ \\
\hline UK & Civil Aviation Authority & http://www.caa.co.uk \\
\hline Europe & Eurostat (Statistical Office of the European Union) & http://www.eurostar.com \\
\hline
\end{tabular}

TABLE 4: An overview of the data sources for high-speed railway.

\begin{tabular}{|c|c|c|}
\hline Region & Organizations & Links \\
\hline Global & International Union of Railways (UIC) & http://www.uic.org/ \\
\hline \multirow{2}{*}{ China } & ransport scientific data sharing system & http://www.transdata.cn. \\
\hline & Chinese Railway Timetable & http://www.chinatt.org \\
\hline Japan & MLIT (Ministry of Land, Infrastructure, Transport and Tourism) & http://www.mlit.go.jp/index_e.html \\
\hline Korea & KORAIL & http://info.korail.com/mbs/english/ \\
\hline \multirow{4}{*}{ Spain } & CKAN Spain railways data & http://thedatahub.org/user/jgcasta \\
\hline & Ministry of Public Works & http://www.fomento.gob.es \\
\hline & RENFE & http://www.renfe.com/ \\
\hline & Ferropedia & http://www.ferropedia.es \\
\hline France & Open data initiative of SCNF & https://data.sncf.com/ \\
\hline Italy & Rete Ferroviaria Italiana & http://www.rfi.it/ \\
\hline UK & National Rail and British Rail & https://datafeeds.networkrail.co.uk \\
\hline \multirow{3}{*}{ Germany } & Deutsche Bahn & https://www.bahn.de/p/view/index.shtml \\
\hline & ICE network & http://www.hochgeschwindigkeitszuege.com \\
\hline & Zugsonar & http://download.odcdn.de/zugsonar/ \\
\hline \multirow{3}{*}{ Europe } & Eurostat (Statistical Office of the European Union) & http://www.eurostar.com \\
\hline & European Rail Timetable & http://www.europeanrailtimetable.eu \\
\hline & EcoPassenger & http://ecopassenger.hafas.de \\
\hline
\end{tabular}

[96], such a model should combine (a) cost-benefit analysis with (b) risk assessment and (c) qualitative impacts of interest to the population.

Recently, [97] integrated timetable formation for air, rail, metro, coach, bus, and ferry in the United Kingdom for a week in October 2010, based on an open-data source (United Kingdom's National Public Transport Data Repository) and Innovata LLC (http://www.innovata-llc.com/). A weighted, directed, temporal, and multimodal transportation network could be constructed in order to analyze the characteristics of integrated public transport system, going beyond traditional views as simple networks or networks of networks [98-100].
Such efforts, on a larger scale, could improve our understanding of global transportation patterns. An overview of the data sources for air transport and HSR is provided in Tables 3 and 4, separately. We think that these data sources could serve as a starting point to build up a comprehensive open-source dataset for large-scale multimodal transport systems. Particularly, the use of Openstreetmap and alike can ease the often tedious bootstrapping process, since it contains rich content of worldwide transportation infrastructure. Integrating Openstreetmap with publicly available GTFS feeds and information about air transportation (schedules) will provide a powerful tool for performing 
TABLE 5: The competition and cooperation effects between air transport and HSR on passenger demand.

\begin{tabular}{|c|c|c|c|c|c|c|}
\hline References & Region & Time frame & Comp. & Coop. & Data type & Main results \\
\hline [19] & ES & $1999-2012$ & $\checkmark$ & & Empirical & $\begin{array}{c}\text { Only } 13.9 \% \text { of HSR passenger demand came from air } \\
\text { transport, indicating services provided by air transport and } \\
\text { HSR are rather independent; HSR can generate demand by } \\
\text { itself. }\end{array}$ \\
\hline$[20]$ & Madrid-Barcelona route & $2003-2013$ & $\checkmark$ & $\checkmark$ & Empirical & $\begin{array}{l}\text { Confirmed the conventional theory that HSR attracts more } \\
\text { passengers than air transport within distances } 300-500 \mathrm{~km} \text {. } \\
\text { The location of HSR station is shifting away from the city } \\
\text { center, with a favored trend of an integrated airport-HSR } \\
\text { station. }\end{array}$ \\
\hline [21] & - & - & $\checkmark$ & $\checkmark$ & Analytical & $\begin{array}{l}\text { When the OD demand between airports is significantly } \\
\text { different, the improved connectivity could narrow the gap } \\
\text { between airports and bring the gateway effect back to } \\
\text { airports with lower demands, while the gateway function } \\
\text { remains at airports with higher demands. }\end{array}$ \\
\hline$[22]$ & - & - & $\checkmark$ & $\checkmark$ & Analytical & $\begin{array}{l}\text { The entry of HSR reduces air traffic, aircraft size, and flight } \\
\text { frequencies but it generates new demand. }\end{array}$ \\
\hline$[23]$ & - & - & & $\checkmark$ & Analytical & $\begin{array}{c}\text { The air traffic in the HSR-accessible market is reduced, } \\
\text { while the traffic in the hub-and-spoke connecting market is } \\
\text { increased. }\end{array}$ \\
\hline$[24]$ & FR, DE, ES, IT, UK & 1995-2009 & $\checkmark$ & & Empirical & $\begin{array}{l}\text { The improved rail travel time has significant impacts on } \\
\text { reducing short haul air traffic in Europe; HSR has } \\
\text { contribution to less domestic air passenger traffic. }\end{array}$ \\
\hline$[25]$ & $\mathrm{JP}$ & 2005 & $\checkmark$ & & Empirical & $\begin{array}{l}\text { Significant airfare reduction probably could stimulate new } \\
\text { demands and shifted demands from rail to air mode; } \mathrm{CO}_{2} \\
\text { emission taxation could reduce air passenger traffic and } \\
\text { increase HSR passenger traffic in large numbers. }\end{array}$ \\
\hline$[26]$ & London-Paris route & 2003-2009 & $\checkmark$ & & Mix & $\begin{array}{l}\text { HSR is rather competitive for the London-Paris market. } \\
\text { Frequency, total travel time, and distance are the main } \\
\text { determinants of travelers' behaviors. Passenger preferences } \\
\text { are rather constant in the time frame. }\end{array}$ \\
\hline$[10]$ & ES & 1999-2009 & $\checkmark$ & & Empirical & $\begin{array}{l}\text { HSR leads to the reduction of air transport operation by } \\
17 \% \text {. Although the travel demand has been increased } \\
\text { substantially, the share of air transport in the total market } \\
\text { has declined. }\end{array}$ \\
\hline$[12]$ & $\mathrm{CN}$ & $1990-2011$ & $\checkmark$ & $\checkmark$ & Mix & $\begin{array}{l}\text { The HSR would be competitive against air transport in } \\
\text { terms of network connectivity, total travel time, and cost } \\
\text { efficiency in short-medium haul market, with passengers } \\
\text { shifting from air transport to HSR. }\end{array}$ \\
\hline$[27]$ & 5 city-pairs, Europe & 1991-2010 & $\checkmark$ & & Empirical & $\begin{array}{l}\text { The overall air traffic is still growing with the development } \\
\text { of HSR; lower HSR travel time would lead to higher drop in } \\
\text { air transport passengers and operations. }\end{array}$ \\
\hline$[28]$ & $\mathrm{DE}$ & $2006-2007$ & $\checkmark$ & & Empirical & $\begin{array}{l}\text { The entry of low-cost carriers leads to drops in rail } \\
\text { passengers. }\end{array}$ \\
\hline [29] & $\mathrm{KR}$ & - & $\checkmark$ & & Empirical & $\begin{array}{l}\text { The improvement of accessibility could increase the } \\
\text { demand of HSR. }\end{array}$ \\
\hline$[30]$ & Seoul-Daegu route & 2004 & $\checkmark$ & & Empirical & $\begin{array}{l}\text { The opening of a new HSR line resulted in a significant } \\
\text { reduction of domestic air traffic demand. }\end{array}$ \\
\hline$[31]$ & London Heathrow airport & - & & $\checkmark$ & Empirical & $\begin{array}{c}\text { In addition to major benefits for airlines, the cooperation } \\
\text { between air transport and HSR also leads to increased } \\
\text { demand for railways. }\end{array}$ \\
\hline
\end{tabular}

large-scale research. Naturally, modeling worldwide transportation requires solving issues such as data heterogeneity and different modeling paradigms/elements. So there is a need for a set of modeling constructs and tools to develop a consistent and concise representation of worldwide transportation. The efforts undertaken in Openstreetmap can serve as a starting point for future developments [101].

Moreover, we need more reliable prediction methods for origin-destination demands, given different infrastructure layouts. Existing models, for example, gravity model and 
TABLE 6: The competition and cooperation effects between air transport and HSR on travel time.

\begin{tabular}{|c|c|c|c|c|c|c|}
\hline References & Region & Time frame & Comp. & Coop. & Data type & Main results \\
\hline [32] & IT & 2012 & $\checkmark$ & & Empirical & $\begin{array}{l}\text { A } 10 \% \text { increase in rail travel time allows airfares to be } \\
\text { increased by a maximum } 4.2 \% \text {; this is true for one month } \\
\text { before flight departure. }\end{array}$ \\
\hline [33] & Madrid-Barcelona route & - & $\checkmark$ & & Mix & $\begin{array}{l}\text { The access/egress time is a key factor in determining spatial } \\
\text { competitiveness of transport modes. }\end{array}$ \\
\hline$[11]$ & 161 city-pairs in Europe & - & $\checkmark$ & $\checkmark$ & Mix & $\begin{array}{c}\text { There are more air services if the travel time of HSR is } \\
\text { longer. }\end{array}$ \\
\hline [24] & FR, DE, ES, IT, UK & 1995-2009 & $\checkmark$ & & Empirical & $\begin{array}{l}\text { The improved rail travel time has significant impacts on } \\
\text { reducing short haul air traffic in Europe. }\end{array}$ \\
\hline$[34]$ & Madrid Barajas airport & 2010-2011 & & $\checkmark$ & Empirical & $\begin{array}{l}\text { Willingness to pay for different attributes of the integrated } \\
\text { air transport and HSR from passengers can be obtained, } \\
\text { among which "connecting time" is the main driver, and thus } \\
\text { schedule coordination is crucial to promote intermodality. }\end{array}$ \\
\hline$[25]$ & JP & 2005 & $\checkmark$ & & Empirical & $\begin{array}{c}\text { Japanese passengers are most sensitive to travel time and } \\
\text { service frequencies and modestly sensitive to price. }\end{array}$ \\
\hline$[12]$ & $\mathrm{CN}$ & $1990-2011$ & $\checkmark$ & $\checkmark$ & Mix & $\begin{array}{l}\text { The HSR would be competitive against air transport in } \\
\text { terms of network connectivity, total travel time, and cost } \\
\text { efficiency in short-medium haul market. }\end{array}$ \\
\hline$[26]$ & London-Paris route & 2003-2009 & $\checkmark$ & & Mix & $\begin{array}{l}\text { Frequency, total travel time, and distance are the main } \\
\text { determinants of travelers' behaviors. }\end{array}$ \\
\hline$[27]$ & 5 city-pairs in Europe & $1991-2010$ & $\checkmark$ & & Empirical & $\begin{array}{l}\text { Lower HSR travel time would lead to higher drop in air } \\
\text { transport passengers and operations. }\end{array}$ \\
\hline$[35]$ & FR & 2006 & $\checkmark$ & & Empirical & $\begin{array}{c}\text { Low travel time of TVG has significant impacts on domestic } \\
\text { air transport in France; Air France tends to divert } \\
\text { remaining flights to its hub airport when it lost competition } \\
\text { against HSR. }\end{array}$ \\
\hline$[36]$ & JP & - & $\checkmark$ & & Empirical & $\begin{array}{l}\text { The access and egress time of HSR has significant impacts } \\
\text { on the modal competition. }\end{array}$ \\
\hline$[37]$ & SE & - & $\checkmark$ & & Empirical & $\begin{array}{c}\text { HSR has lower operational costs per available seat } \\
\text { kilometers. Travel time is the primary competition. HSR } \\
\text { would win over some travel from airlines. }\end{array}$ \\
\hline$[31]$ & London Heathrow airport & - & & $\checkmark$ & Empirical & $\begin{array}{l}\text { Main benefits for airlines include, but are not limited to, } \\
\text { increased connectivity and catchment area and improved } \\
\text { accessibility. These benefits have the potential to reduce the } \\
\text { travel time. }\end{array}$ \\
\hline
\end{tabular}

its variants [102-104], predict the demand between city pairs based on demography and societal data, yet neglecting the available transportation options. Naturally, the ease to travel between two points increases the attractiveness for passengers. Recent work suggests that the inclusion of social network data and telecommunication data can improve the accuracy of origin-destination matrix estimation significantly [105-107].

With the improvement of the (free) available data for research, we will need further (open-source) tools for simulation of transportation at different levels of scale, from microscale to macroscale. To sum up, data and methods/implementations should not be hidden behind paywalls, but the goal should be to make research accessible to all research teams, independent of the available funding.

\subsection{Analyzing Emerging Transportation Modes and New} Business Models. With increased requirements of passenger mobility, new transportation modes and new business models are emerging. One successful example is the low-cost coach MeinFernbus in Germany. Starting from 2012, the lowcost coach has spread in Germany and is extending its network across Europe [108]. Because of the cheap ticket price, the new entry of MeinFernbus has attracted passengers from car users and conventional rails. The major question is how long the company can afford these cheap prices and which pricing strategy is chosen after cutting out the other competitors from the German market. In France, by learning the pricing strategies from low-cost airlines, lowcost HSR is emerging as well $[109,110]$. This could lead to intramodal competition among different HSR operators [40]. Night-train HSR is another novel business model and it is shown that night-train HSR could have a cost advantage over air traffic in 2025 [111]. The effects are much similar with the entry of low-cost airlines, which was dominated by traditional full service airlines, while the entry of HSR is competitive against short haul air travel (approx. 1,000 km). Moreover, as our introductory example shows (see Figure 1), 
TABLE 7: The competition and cooperation effects between air transport and HSR on price.

\begin{tabular}{|c|c|c|c|c|c|c|}
\hline References & Region & Time frame & Comp. & Coop. & Data type & Main results \\
\hline$[32]$ & IT & 60 days & $r$ & & Empirical & $\begin{array}{l}\text { A } 10 \% \text { increase in rail travel time allows airfares to be } \\
\text { increased by a maximum } 4.2 \% \text {; this is true for one month } \\
\text { before flight departure. }\end{array}$ \\
\hline [38] & IT & 60 days & $\checkmark$ & & Empirical & $\begin{array}{l}\text { Fares are significantly reduced by airlines when under direct } \\
\text { competition with HSR. }\end{array}$ \\
\hline [39] & $\mathrm{CN}$ & 2011 & $\checkmark$ & & Empirical & $\begin{array}{l}\text { Mean airfares for the Jing-Hu HSR routes declined approx. } \\
29 \% \text { upon the launch of HSR, but rebounded by approx. } \\
20 \% \text { after the Wenzhou HSR accidents; low-cost carriers are } \\
\text { more responsive to the HSR events than other carriers. }\end{array}$ \\
\hline$[40]$ & IT & 2009-2012 & $\checkmark$ & & Empirical & $\begin{array}{l}\text { The on-board services have been increased; the HSR fares } \\
\text { have been reduced by } 31 \% \text {. }\end{array}$ \\
\hline [25] & $\mathrm{JP}$ & 2005 & $\checkmark$ & & Empirical & $\begin{array}{l}\text { Japanese passengers are most sensitive to travel time and } \\
\text { service frequencies and modestly sensitive to price. }\end{array}$ \\
\hline$[41]$ & Iberian Peninsula, Europe & - & $\checkmark$ & $\checkmark$ & Empirical & $\begin{array}{l}\text { With a more holistic intermodal product, the benefits of } \\
\text { intermodality can be best captured and the competitiveness } \\
\text { of HSR decreases with the travel costs. }\end{array}$ \\
\hline$[42]$ & $\mathrm{CN}$ & - & $\checkmark$ & & Analytical & $\begin{array}{l}\text { Airfare decreases and rail fare increases in airport access } \\
\text { time; airfare decreases in rail speed if the marginal cost of } \\
\text { HSR comparing with rail speed is not too large. The profit of } \\
\text { air transport is higher with price discrimination between } \\
\text { leisure passengers and business passengers than without it. }\end{array}$ \\
\hline [26] & London-Paris route & 2003-2009 & $\checkmark$ & & Mix & $\begin{array}{l}\text { Leisure passengers are more heterogeneous concerning } \\
\text { average fares than business passengers. }\end{array}$ \\
\hline$[43]$ & Madrid-Barcelona route & 2003 & $\checkmark$ & & Empirical & $\begin{array}{c}\text { Prices and service frequency are among the most important } \\
\text { variables in the competition. }\end{array}$ \\
\hline [28] & $\mathrm{DE}$ & 2006-2007 & $r$ & & Empirical & $\begin{array}{c}\text { The entry of low-cost carriers put pressure on rail ticket } \\
\text { prices. }\end{array}$ \\
\hline
\end{tabular}

TABLE 8: The competition and cooperation effects between air transport and HSR on seats and frequencies.

\begin{tabular}{|c|c|c|c|c|c|c|}
\hline References & Region & Time frame & Comp. & Coop. & Data type & Main results \\
\hline$[44]$ & ES & 2010 & $r$ & & Empirical & $\begin{array}{l}\text { The developed integrated optimization model is able to } \\
\text { predict the airline's response to the entry of HSR, by } \\
\text { fine-tuning schedules, fleets, and fares. }\end{array}$ \\
\hline [38] & IT & 60 days & $\checkmark$ & & Empirical & $\begin{array}{l}\text { Intramodal competition of two HSR operators showed that } \\
\text { capacity and frequency are strategic variables. }\end{array}$ \\
\hline$[45]$ & FR, DE, IT, ES & $2002-2010$ & $\checkmark$ & $\checkmark$ & Empirical & $\begin{array}{c}\text { The number of seats was reduced, but with minor influence } \\
\text { on flight frequencies. The reduction of services is greater at } \\
\text { hub airports. HSR can also provide feeding services to long } \\
\text { haul flights in hub airports. }\end{array}$ \\
\hline$[22]$ & - & - & $\checkmark$ & & Analytical & $\begin{array}{l}\text { The entry of HSR reduces air traffic, aircraft size, and flight } \\
\text { frequencies. }\end{array}$ \\
\hline [11] & 161 city-pairs in Europe & - & $\checkmark$ & $\checkmark$ & Mix & $\begin{array}{l}\text { There are more airline seats and number of flights if the } \\
\text { travel time of HSR is longer. }\end{array}$ \\
\hline$[25]$ & Japan & 2005 & $\checkmark$ & & Empirical & $\begin{array}{c}\text { Japanese passengers are most sensitive to travel time and } \\
\text { service frequencies and modestly sensitive to price. }\end{array}$ \\
\hline [43] & Madrid-Barcelona route & 2003 & $\checkmark$ & & Empirical & $\begin{array}{l}\text { Prices and service frequency are among the most important } \\
\text { variables in the competition. }\end{array}$ \\
\hline$[26]$ & London-Paris route & 2003-2009 & $\checkmark$ & & Mix & $\begin{array}{l}\text { Frequency, total travel time, and distance are the main } \\
\text { determinants of travelers' behaviors. }\end{array}$ \\
\hline$[31]$ & London Heathrow airport & - & & $\checkmark$ & Empirical & $\begin{array}{l}\text { The cooperation between air transport and HSR can bring } \\
\text { major benefits for the airlines, such as additional capacity } \\
\text { and freed slots. }\end{array}$ \\
\hline
\end{tabular}


TABLE 9: The competition and cooperation effects between air transport and HSR on environment and social welfare.

\begin{tabular}{|c|c|c|c|c|c|c|}
\hline References & Region & Time frame & Comp. & Coop. & Data type & Main results \\
\hline [22] & - & - & $\checkmark$ & & Analytical & $\begin{array}{l}\text { If HSR is not sufficiently greener than air transport, the } \\
\text { introduction of HSR will increase the environmental } \\
\text { pollution and reduce social welfare; otherwise it will } \\
\text { increase the environmental benefit. When the increase } \\
\text { of the emission of HSR due to the increased speed is } \\
\text { sufficiently high, the competition would be detrimental } \\
\text { to the environment. }\end{array}$ \\
\hline [5] & US & - & $\checkmark$ & & Analytical & $\begin{array}{l}\text { There are cases with significant HSR penetration; the } \\
\text { national long-term } \mathrm{CO}_{2} \text { emissions and costs could be } \\
\text { decreased. }\end{array}$ \\
\hline$[46]$ & US & - & $\checkmark$ & & Mix & $\begin{array}{c}\text { The greenhouse gas emissions could be reduced in US } \\
\text { with HSR. }\end{array}$ \\
\hline [23] & - & - & & $\checkmark$ & Analytical & $\begin{array}{c}\text { The welfare is improved with low substitutability; when } \\
\text { the substitutability is high, the cooperation would } \\
\text { improve the welfare if the hub airport is heavily } \\
\text { capacity-constrained. }\end{array}$ \\
\hline [47] & - & - & $\checkmark$ & $\checkmark$ & Analytical & $\begin{array}{l}\text { The cooperation could improve the welfare of } \\
\text { international passengers. }\end{array}$ \\
\hline [48] & Madrid-Malaga route & - & & $\checkmark$ & Analytical & $\begin{array}{l}\text { The welfare would be very likely to be enhanced for } \\
\text { airports with capacity constraints. The environmental } \\
\text { effects could be positive or negative. }\end{array}$ \\
\hline [49] & Worldwide & 2010 & & $\checkmark$ & Empirical & $\begin{array}{l}\text { Mode substitution from air to rail is likely to play a } \\
\text { greater role in the air pollution reduction around } \\
\text { airports. }\end{array}$ \\
\hline$[50]$ & Madrid Barajas airport & - & & $\checkmark$ & Mix & $\begin{array}{l}\text { With HSR, passengers traveling with aircraft and } \\
\text { private car are reduced, leading to environmental } \\
\text { benefits. Increasing the travel cost of private car is } \\
\text { picked up by air transport rather than HSR, leading to } \\
\text { negative environmental impacts. }\end{array}$ \\
\hline$[51]$ & US & - & $\checkmark$ & & Mix & $\begin{array}{c}\text { A HSR system with current technologies would provide } \\
\text { significant environmental benefits over existing modes, } \\
\text { when the ridership is high. }\end{array}$ \\
\hline$[52]$ & London Heathrow airport & - & $\checkmark$ & $\checkmark$ & Analytical & $\begin{array}{l}\text { Significant savings (delays and costs) can be obtained } \\
\text { even with rather modest substitution. }\end{array}$ \\
\hline [53] & $\mathrm{JP}$ & $1999-2007$ & - & - & Mix & $\begin{array}{l}\text { The operation of aviation industry is socially efficient in } \\
\text { the observed period, although its } \mathrm{CO}_{2} \text { emission per } \\
\text { passenger kilometer is higher than the one with rail. }\end{array}$ \\
\hline$[54]$ & $27 \mathrm{EU}$ countries & 2020 (scenarios) & $\checkmark$ & & Analytical & $\begin{array}{l}\text { Development of the HSR network across Europe should } \\
\text { be encouraged in order to maximize the overall social } \\
\text { welfare. }\end{array}$ \\
\hline$[31]$ & London Heathrow airport & - & & $\checkmark$ & Empirical & $\begin{array}{l}\text { Increased connectivity and catchment area, improved } \\
\text { accessibility, and reduced local air pollution. }\end{array}$ \\
\hline [55] & - & - & & $\checkmark$ & Simulation & $\begin{array}{c}\text { The level of passengers delays would be increased with } \\
\text { intermodal passenger movement, while social benefits } \\
\text { can be expected at airports with large amounts of short } \\
\text { haul flights. }\end{array}$ \\
\hline
\end{tabular}

the competition range can even go beyond $1,000 \mathrm{~km}$ in specific cases, a distance which was difficult to imagine in the last century. Furthermore, the analysis of competition between air transport and HSR has to take into account the urban transportation from areas with higher population densities. Airports tend to be built far outside city centers, mainly for concerns about noise/emission and also because of lack of space. HSR stations, on the other hand, often are closer to the people and thus have an advantage in access times.
Night-train HSR would raise direct competition against air traffic on medium haul flight routes even further (approx. $2,000 \mathrm{~km}$ ).

Therefore, a unified modeling framework for intra/intermodal competition/cooperation between existing transportation modes and new emerging ones, with the consideration of multiple competitors [23] and additional transportation modes for estimating real access times, is of significant importance in future work. Another direction is to consider 
risks and uncertainties in a stochastic modeling framework [54].

\subsection{Passenger-Oriented Multimodal Transportation Systems.} The European Commission has a goal that $90 \%$ of travelers within Europe are able to complete their journey, door-todoor within 4 hours [112]. Multimodal transportation systems should provide maximum convenience for passengers on their door-to-door travels. Therefore, the multilayer structure of networks should be considered [113]. One aspect is to study the driving factors to simulate new passenger demand [24] and the dynamics of passenger demand shifting between different transportation modes [19]. Currently, in the field of air transport, passenger-oriented performance metrics are drawing more attention [114-116]. A future concept in Europe is the 24/7 aircraft, which can be operated 24 hours in a day and 7 days in a week, without the restriction of airport curfews [117]. The 24/7 aircraft has quiet and short takeoff/landing distances and thus it allows night operations. Moreover, it uses massive flow control and it has mission adaptation capabilities [117].

We envision an adaptive multimodal transportation system where passengers buy door-to-door or region-to-region services. This would allow airlines and air navigation service providers to flexibly trade-off airport and airspace resources within a region; this would also leverage mobility of passengers within regional airport systems by using local ground and air transportation and increase the flexibility of airline flight planning and disruption management. An interesting case study from China is an integrated multimodal transportation system, as the skeleton for the cooperative development of Beijing, Tianjin, and Hebei Province (Jing-Jin-Ji) [118].

\subsection{Resilience of Multimodal, Multilayered Transportation} Systems. It is critical that multimodal transport systems still function well under disruptions or failures. The first fatal HSR accident which happened in China was on 23 July 2011: two high-speed trains derailed each other and four cars fell off the Ou river bridge in Wenzhou, killing 40 people and 192 injured. Reference [39] showed that the mean airfares for the routes along the Jing-hu HSR declined approx. 29\% upon the launch of HSR, but rebounded by approx. $20 \%$ after the Wenzhou HSR accidents in China. Furthermore, $[119,120]$ explored the potential of substituting flights with ground transportation modes in order to mitigate congestion and reduce delay, when there are severe shortfalls in airport capacity or airport closure temporarily. An optimization model is proposed to determine which flights to cancel or to be replaced by ground transportation modes, with the minimization of incurred cost as the objective function. This model was applied to a representative US airport. Results showed that the real-time intermodal substitution could save around $8 \%-14 \%$ of the disruption cost, compared with the case without the intermodal substitution. These effects are similar to the gains with multiple airport regions in air transportation, where nearby airports can compensate with each other [121].
It is very interesting and challenging to investigate further real-time modal substitution in multimodal transport systems at a larger scale. Naturally, this directly addresses the issue of cooperation between operators in different transportation modes. This fact, together with the problem of cascading failures in multimodal, interdependent networks [122], requires much more research. Complex network-based techniques can significantly contribute to this challenge [123126]. Particularly, modeling the system as a temporal complex network can help to better predict the resilience of the system under failures [127].

3.5. The Role of ICT in Multimodal Transportation Systems. Smartphones already play a critical role in multimodal transport systems. Reference [128] showed that the introduction of simple ICT (Information and Communication Technologies) solutions in multimodal transportation systems can noticeably improve its overall behavior. The extraordinary growth in excessive smartphone usage has led researchers to the idea of performing data mining on top of user's mobility data. Examples for such analyses are physical activity monitoring [129], regional travel demand analysis/forecasting [130, 131], and personal impact monitoring [132]. Therefore, a major goal is to motivate changes in travel behavior and more conscious use of resources, leading towards the vision of green transportation [133].

There are still many challenges regarding the determination of a precise location and travel modes on mobile phones, in particular with energy efficient methods. Moreover, position determination and mode detection should not be looked at separately: combining imprecise data from both can lead to better overall results. Such ideas have been implemented in navigation systems, which automatically snap to the next street, if the GPS does not give an accurate (or a nonsense) position. Similarly, for modality detection, if a device believes that the user is in a train, it can more accurately detect the position by snapping to train lines (if such information is available online/offline). Furthermore, it would be interesting to investigate how the usage of smartphones influences the competition/cooperation relationship in multimodal transport systems.

\section{Conflicts of Interest}

The authors declare that there are no conflicts of interest regarding the publication of this paper.

\section{Acknowledgments}

This study is supported by the National Natural Science Foundation of China (Grants no. 61650110516, no. 61601013, no. 61521091, and no. 91538204).

\section{References}

[1] T. Litman, "Towards more comprehensive and multi-modal transport evaluation," Tech. Rep., Victoria Transport Policy Institute, 2014. 
[2] S. Tang, S. D. Boyles, and N. Jiang, "High-speed rail cost recovery time based on an integer optimization model," Journal of Advanced Transportation, vol. 49, no. 5, pp. 634-647, 2015.

[3] Y.-S. Cheng, B. P. Y. Loo, and R. Vickerman, "High-speed rail networks, economic integration and regional specialisation in China and Europe," Travel Behaviour and Society, vol. 2, no. 1, pp. 1-14, 2015.

[4] G. Chen and J. De Abreu E Silva, "Regional impacts of highspeed rail: a review of methods and models," Transportation Letters, vol. 5, no. 3, pp. 131-143, 2013.

[5] V. Krishnan, E. Kastrouni, V. D. Pyrialakou, K. Gkritza, and J. D. McCalley, "An optimization model of energy and transportation systems: assessing the high-speed rail impacts in the United States," Transportation Research Part C: Emerging Technologies, vol. 54, pp. 131-156, 2015.

[6] Q. Cui, Y.-M. Wei, C.-1. Yu, and Y. Li, "Measuring the energy efficiency for airlines under the pressure of being included into the EU ETS," Journal of Advanced Transportation, vol. 50, no. 8, pp. 1630-1649, 2016.

[7] B. van Wee, "Accessible accessibility research challenges," Journal of Transport Geography, vol. 51, pp. 9-16, 2016.

[8] C.-W. Kuo and M.-L. Tang, "Relationships among service quality, corporate image, customer satisfaction, and behavioral intention for the elderly in high speed rail services," Journal of Advanced Transportation, vol. 47, no. 5, pp. 512-525, 2013.

[9] M. Givoni, "Development and impact of the modern highspeed train: a review," Transport Reviews, vol. 26, no. 5, pp. 593611, 2006.

[10] J. L. Jiménez and O. Betancor, "When trains go faster than planes: the strategic reaction of airlines in Spain," Transport Policy, vol. 23, pp. 34-41, 2012.

[11] F. Dobruszkes, C. Dehon, and M. Givoni, "Does European highspeed rail affect the current level of air services? An EU-wide analysis," Transportation Research Part A: Policy and Practice, vol. 69, pp. 461-475, 2014.

[12] X. Fu, A. Zhang, and Z. Lei, "Will China's airline industry survive the entry of high-speed rail?" Research in Transportation Economics, vol. 35, no. 1, pp. 13-25, 2012.

[13] A. Ghobrial, "An aggregate demand model for domestic airlines," Journal of Advanced Transportation, vol. 26, no. 2, pp. 105-119, 1992.

[14] T. Li, H. Baik, and A. A. Trani, "A method to estimate the historical US air travel demand," Journal of Advanced Transportation, vol. 47, no. 3, pp. 249-265, 2013.

[15] A. D. Perl and A. R. Goetz, "Corridors, hybrids and networks: three global development strategies for high speed rail," Journal of Transport Geography, vol. 42, pp. 134-144, 2015.

[16] J. Preston, "High Speed Rail in Britain: about time or a waste of time?" Journal of Transport Geography, vol. 22, pp. 308-311, 2012.

[17] G. Ollivier, J. Sondhi, and N. Zhou, "High-speed railways in china: a look at construction costs," in China Transport Topics, vol. 9, pp. 1-8, 2014.

[18] J. Campos and G. De Rus, "Some stylized facts about high-speed rail: a review of HSR experiences around the world," Transport Policy, vol. 16, no. 1, pp. 19-28, 2009.

[19] J. I. Castillo-Manzano, R. Pozo-Barajas, and J. R. Trapero, "Measuring the substitution effects between High Speed Rail and air transport in Spain," Journal of Transport Geography, vol. 43, pp. 59-65, 2015.
[20] J. M. Garcia, “The integration of a high-speed train station in valencia city," Urban Transport XXI, vol. 146, no. 3, 2015.

[21] M. Takebayashi, "Multiple hub network and high-speed railway: connectivity, gateway, and airport leakage," Transportation Research Part A: Policy and Practice, vol. 79, pp. 55-64, 2015.

[22] T. D’Alfonso, C. Jiang, and V. Bracaglia, "Would competition between air transport and high-speed rail benefit environment and social welfare?" Transportation Research Part B: Methodological, vol. 74, pp. 118-137, 2015.

[23] C. Jiang and A. Zhang, "Effects of high-speed rail and airline cooperation under hub airport capacity constraint," Transportation Research Part B: Methodological, vol. 60, pp. 33-49, 2014.

[24] R. R. Clewlow, J. M. Sussman, and H. Balakrishnan, "The impact of high-speed rail and low-cost carriers on European air passenger traffic," Transport Policy, vol. 33, pp. 136-143, 2014.

[25] X. Fu, T. H. Oum, and J. Yan, "An analysis of travel demand in japans inter-city market: empirical estimation and policy simulation," Journal of Transport, Economics and Policy, vol. 48, no. 1, pp. 97-113, 2014.

[26] C. Behrens and E. Pels, "Intermodal competition in the LondonParis passenger market: high-speed rail and air transport," Journal of Urban Economics, vol. 71, no. 3, pp. 278-288, 2012.

[27] F. Dobruszkes, "High-speed rail and air transport competition in Western Europe: a supply-oriented perspective," Transport Policy, vol. 18, no. 6, pp. 870-879, 2011.

[28] H. Friederiszick, T. Gantumur, R. Jayaraman, L.-H. Roeller, and $\mathrm{J}$. Weinmann, Railway Alliances in Ec Long-Distance Passenger Transport: A Competitive Assessment Post-Liberalization 2010, Esmt White Paper No. Wp-109-01, ESMT European School of Management And Technology, 2009.

[29] J. Chang and J.-H. Lee, "Accessibility analysis of Korean highspeed rail: a case study of the Seoul metropolitan area," Transport Reviews, vol. 28, no. 1, pp. 87-103, 2008.

[30] Y. Park and H.-K. Ha, "Analysis of the impact of high-speed railroad service on air transport demand," Transportation Research Part E: Logistics, vol. 42, no. 2, pp. 95-104, 2006, selected papers from the 8th ATRS Conference.

[31] M. Givoni and D. Banister, "Airline and railway integration," Transport Policy, vol. 13, no. 5, pp. 386-397, 2006.

[32] C. Capozza et al., "The effect of rail travel time on airline fares: first evidence from the italian passenger market," Working paper SIET, 2015.

[33] J. C. Martin, C. Roman, J. C. Garcia-Palomares, and J. Gutierrez, "Spatial analysis of the competitiveness of the high-speed train and air transport: the role of access to terminals in the Madrid-Barcelona corridor," Transportation Research Part A: Policy and Practice, vol. 69, pp. 392-408, 2014.

[34] C. Román and J. C. Martín, "Integration of HSR and air transport: understanding passengers' preferences," Transportation Research Part E: Logistics and Transportation Review, vol. 71, pp. 1290-141, 2014.

[35] P. Zembri, "New objectives of the french high-speed rail system within the framework of a highly centralized network: a substitute for the domestic air transport market?" in ERSANECTAR Special Session on High-Speed Rail as A New Transport Network, 2010.

[36] R. Clever and M. M. Hansen, "Interaction of air and high-speed rail in Japan," Transportation Research Record, vol. 2043, pp. 1$12,2008$.

[37] O. Fröidh, "Perspectives for a future high-speed train in the Swedish domestic travel market," Journal of Transport Geography, vol. 16, no. 4, pp. 268-277, 2008. 
[38] A. S. Bergantino, C. Capozza, and M. Capurso, "The impact of open access on intra- and inter-modal rail competition. A national level analysis in Italy," Transport Policy, vol. 39, pp. 7786, 2015.

[39] F. Wei, J. Chen, and L. Zhang, "The pricing effects of competition from high-speed rails: evidence from the chinese airline market1," Tech. Rep., 2015.

[40] E. Cascetta and P. Coppola, "Competition on fast track: an analysis of the first competitive market for HSR services," Procedia-Social and Behavioral Sciences, vol. 111, pp. 176-185, 2014.

[41] R. F. Alland and F. M. M. Vilaca E Moura, "Optimizing highspeed rail and air transport intermodal passenger network design," Transportation Research Record, vol. 2448, pp. 11-20, 2014.

[42] H. Yang and A. Zhang, "Effects of high-speed rail and air transport competition on prices, profits and welfare," Transportation Research B: Methodological, vol. 46, no. 10, pp. 1322-1333, 2012.

[43] F. Pagliara, J. M. Vassallo, and C. Román, "High-speed rail versus air transportation," Transportation Research Record, vol. 2289, pp. 10-17, 2012.

[44] L. Cadarso, V. Vaze, C. Barnhart, and Á. Marín, “Integrated airline scheduling: considering competition effects and the entry of the high speed rail," Transportation Science, vol. 51, no. 1, pp. 132-154, 2017.

[45] D. Albalate, G. Bel, and X. Fageda, "Competition and cooperation between high-speed rail and air transportation services in Europe," Journal of Transport Geography, vol. 42, pp. 166-174, 2015.

[46] C. Kamga and M. A. Yazici, "Achieving environmental sustainability beyond technological improvements: potential role of high-speed rail in the United States of America," Transportation Research Part D: Transport and Environment, vol. 31, pp. 148164, 2014.

[47] M. Takebayashi, "The future relations between air and rail transport in an island country," Transportation Research Part A: Policy and Practice, vol. 62, pp. 20-29, 2014.

[48] M. P. Socorro and M. F. Viecens, "The effects of airline and high speed train integration," Transportation Research Part A: Policy and Practice, vol. 49, pp. 160-177, 2013.

[49] M. Givoni, F. Dobruszkes, and I. Lugo, "Uncovering the real potential for airrail substitution: an exploratory analysis," in Energy, Transport, and the Environment, O. Inderwildi and S. D. King, Eds., pp. 495-512, Springer, London, UK, 2012.

[50] M. Zanin, R. Herranz, and S. Ladousse, "Environmental benefits of air-rail intermodality: the example of Madrid Barajas," Transportation Research Part E: Logistics and Transportation Review, vol. 48, no. 5, pp. 1056-1063, 2012.

[51] M. Chester and A. Horvath, "High-speed rail with emerging automobiles and aircraft can reduce environmental impacts in california's future," Environmental Research Letters, vol. 7, no. 3, Article ID 034012, 2012.

[52] M. Janic, "Assessing some social and environmental effects of transforming an airport into a real multimodal transport node," Transportation Research Part D: Transport and Environment, vol. 16, no. 2, pp. 137-149, 2011.

[53] H.-K. Ha, Y. Yoshida, and A. Zhang, "Social efficiency benchmarking of Japanese domestic transport services: a comparison of rail and air," Transportation Research Part D: Transport and Environment, vol. 16, no. 7, pp. 554-561, 2011.
[54] N. Adler, E. Pels, and C. Nash, "High-speed rail and air transport competition: Game engineering as tool for cost-benefit analysis," Transportation Research Part B: Methodological, vol. 44, no. 7, pp. 812-833, 2010.

[55] A. Cokasova, Analysis of passenger viewpoints and of the practical shift in air rail intermodal transport [Ph.D. thesis], University of Zilina, 2006.

[56] S. Wandelt, X. Sun, and J. Zhang, "Evolution of domestic airport networks: a review and comparative analysis," Transportmetrica B: Transport Dynamics, 2017.

[57] S. Wandelt and X. Sun, "Evolution of the international air transportation country network from 2002 to 2013," Transportation Research Part E: Logistics and Transportation Review, vol. 82, pp. 55-78, 2015.

[58] X. Sun, S. Wandelt, and F. Linke, "On the topology of air navigation route systems," Proceedings of the Institution of Civil Engineers-Transport, vol. 170, no. 1, pp. 46-59, 2017.

[59] X. Sun and S. Wandelt, "Network similarity analysis of air navigation route systems," Transportation Research Part E: Logistics and Transportation Review, vol. 70, pp. 416-434, 2014.

[60] W. Rothengatter, CompetItion between Airlines And High-Speed Rail, chapter 18, Routledge, Oxford, UK, 2011.

[61] B. Guirao, "Spain: highs and lows of 20years of HSR operation," Journal of Transport Geography, vol. 31, pp. 201-206, 2013.

[62] K. Barrow, "France faces tough choices over future of TGV," International Railway Journal, vol. 55, no. 1, 2015.

[63] G. Ollivier, R. Bullock, Y. Jing, J. Sondhri, and N. Zhou, "Chinese high-speed: an evaluation of traffic," International Railway Journal, vol. 55, no. 2, 2015.

[64] T. Takatsu, "The history and future of high-speed railways in Japan," Japan Railway \& Transport Review, vol. 48, pp. 6-21, 2007.

[65] J. Y. Chung and T. Whang, "The impact of low cost carriers on Korean Island tourism," Journal of Transport Geography, vol. 19, no. 6, pp. 1335-1340, 2011.

[66] L. S. Thompson, "High-speed rail (hsr) in the united states why isn't there more?" Japan Railway \& Transport Review, vol. 0, pp. 32-39, 1994.

[67] X. Fu, Z. Lei, K. Wang, and J. Yan, "Low cost carrier competition and route entry in an emerging but regulated aviation market $\mathrm{c}$ the case of China," Transportation Research Part A: Policy and Practice, vol. 79, pp. 3-16, 2015, selected papers from the Air Transport Research Society World Conference, Bergamo (Italy) and World Conference on Transport Research, Rio de Janeiro (Brazil), 2013.

[68] F. Dobruszkes, M. Givoni, and C. Dehon, "Assessing the competition between high-speed rail and airlines: a critical perspective," in Evaluating High-Speed Rail: Interdisciplinary Perspectives, pp. 159-174, Routledge, 2017.

[69] J. J. Louviere, D. A. Hensher, and J. Swait, Stated Choice Methods, Cambridge University Press, 2000.

[70] R. Merkert and M. Beck, "Value of travel time savings and willingness to pay for regional aviation," Transportation Research Part A: Policy and Practice, vol. 96, pp. 29-42, 2017.

[71] J. Banks, J. Carson, B. Nelson, and D. Nicol, Discrete-Event System Simulation, Prentice Hall, 5th edition, 2009.

[72] M. Chester and M. S. Ryerson, "Environmental assessment of air and high-speed rail corridors," Transportation Research Board, 2013.

[73] M. Givoni, "Comparison of the environmental impact from aircraft and high-speed train operation," in ECEEE Summer Study, Panel 3 Land Use, Transportation And Mobility, 2003. 
[74] F. Dobruszkes and M. Givoni, "Competition, integration, substitution: myths and realities concerning the relationship between high-speed rail and air transport in Europe," in Sustainable Aviation Futures, vol. 4 of Transport and Sustainability, pp. 175-197, Emerald Group Publishing, 2013.

[75] M. Janic, "High-speed rail and air passenger transport: a comparison of the operational environmental performance," Proceedings of the Institution of Mechanical Engineers, Part F: Journal of Rail and Rapid Transit, vol. 217, no. 4, pp. 259-269, 2003.

[76] M. E. Eagan, "A comparison of noise impacts of intercity rail and short-haul air travel," in Transportation Research Board Annual Meeting, Washington, DC, USA, 2011.

[77] K. A. Small, "Valuation of travel time," Economics of Transportation, vol. 1, no. 1-2, pp. 2-14, 2012.

[78] M. Börjesson, M. Fosgerau, and S. Algers, "On the income elasticity of the value of travel time," Transportation Research Part A: Policy and Practice, vol. 46, no. 2, pp. 368-377, 2012.

[79] K. W. Axhausen, S. Hess, A. König, G. Abay, J. J. Bates, and M. Bierlaire, "Income and distance elasticities of values of travel time savings: new Swiss results," Transport Policy, vol. 15, no. 3, pp. 173-185, 2008.

[80] P. A. L. Abrantes and M. R. Wardman, "Meta-analysis of UK values of travel time: an update," Transportation Research Part A: Policy and Practice, vol. 45, no. 1, pp. 1-17, 2011.

[81] L. Hultkrantz, "A note on high-speed rail investments and travelers value of time," Journal of Rail Transport Planning Management, vol. 3, no. 1-2, pp. 14-21, 2013.

[82] C. Román, J. C. Martín, R. Espino et al., "Valuation of travel time savings for intercity travel: the Madrid-Barcelona corridor," Transport Policy, vol. 36, pp. 105-117, 2014.

[83] C. Roman, R. Espino, and J. C. Martin, "Analyzing competition of the high speed train with alternative modes. the case of the corridor madrid-zaragoza-barcelona," in Proceedings of the 11th World Conference on Transport Research, 2007.

[84] M. de Bok, A. Costa, S. Melo, and V. Palma, "Estimation of a mode choice model for long distance travel in portugal," in Proceedings of the World Conference of Transport Research, Lisbon, Portugal, 2010.

[85] C. Rohr, J. Fox, A. Daly, B. Patruni, S. Patil, and F. Tsang, "Modelling long-distance travel in the uk," Proceedinghs of the TRB 2013 Annual Meeting, 2013.

[86] C. Nash, "When to invest in high-speed rail links and networks?" Proceeding of the 18th International ITF/OECD Symposium on Transport Economics and Policy, 2010.

[87] M. Sánchez-Borràs, C. Nash, P. Abrantes, and A. López-Pita, "Rail access charges and the competitiveness of high speed trains," Transport Policy, vol. 17, no. 2, pp. 102-109, 2010.

[88] E. Cascetta and P. Coppola, "High speed railways demand forecasting in a competitive market: the Italian case study," in Proceedings of the European Transport Conference, Glasgow, UK, 2010.

[89] I. Cabanne, "A long term model for long distance travel in France," in Proceedings of the European Transport Conference, Strasbourg, France, 2003.

[90] M. Borjesson, "Forecasting demand for high speed rail," Transportation Research Part A: Policy and Practice, vol. 70, pp. 81-92, 2014.

[91] Q. Zhang, H. Yang, and Q. Wang, "Impact of high-speed rail on China's big three airlines," Transportation Research Part A: Policy and Practice, vol. 98, pp. 77-85, 2017.
[92] M. Wardman, "Public transport values of time," Transport Policy, vol. 11, no. 4, pp. 363-377, 2004.

[93] T. Ida and M. Suda, "The cost structure of the japanese railway industry: the economies of scale and scope and the regional gap of the Japan railway after the privatization," International Journal of Transport Economics, vol. 31, no. 1, pp. 23-37, 2004.

[94] S. Goldman, "China transportation: airlines - high speed rail less of a threat than you may think," Tech. Rep., 2010.

[95] Z. Neal, "The devil is in the details: Differences in air traffic networks by scale, species, and season," Social Networks, vol. 38, no. 1, pp. 63-73, 2014.

[96] E. Bruun and M. Givoni, "Sustainable mobility: six research routes to steer transport policy," Nature, vol. 523, no. 7558, pp. 29-31, 2015.

[97] R. Gallotti and M. Barthelemy, "The multilayer temporal network of public transport in Great Britain," Scientific Data, vol. 2, Article ID 140056, 2015.

[98] M. Small, L. Hou, and L. Zhang, "Random complex networks," National Science Review, vol. 1, no. 3, pp. 357-367, 2014.

[99] J. Gao, D. Li, and S. Havlin, "From a single network to a network of networks," National Science Review, vol. 1, no. 3, pp. 346-356, 2014.

[100] X. Wang, "Towards data-driven identification and control of complex networks," National Science Review, vol. 1, no. 3, pp. 335-336, 2014.

[101] S. Wandelt, Z. Wang, and X. Sun, "Worldwide railway skeleton network: Extraction methodology and preliminary analysis," IEEE Transactions on Intelligent Transportation Systems, vol. 99, pp. 1-11, 2016.

[102] J. H. Bergstrand, "The gravity equation in international trade: some microeconomic foundations and empirical evidence," The Review of Economics and Statistics, vol. 67, no. 3, pp. 474-481, 1985.

[103] M. G. McNally, “The Four-Step Model,” in Handbook of Transport Modelling, vol. 1 of Handbooks in Transport, pp. 35-53, Emerald Group Publishing, 2007.

[104] J. P. LeSage and R. K. Pace, "Spatial econometric modeling of origin-destination flows," Journal of Regional Science, vol. 48, no. 5, pp. 941-967, 2008.

[105] F. Calabrese, G. Di Lorenzo, L. Liu, and C. Ratti, "Estimating origin-destination flows using mobile phone location data," IEEE Pervasive Computing, vol. 10, no. 4, pp. 36-44, 2011.

[106] M. S. Iqbal, C. F. Choudhury, P. Wang, and M. C. González, "Development of origin-destination matrices using mobile phone call data," Transportation Research Part C: Emerging Technologies, vol. 40, pp. 63-74, 2014.

[107] F. Calabrese, L. Ferrari, and V. D. Blondel, "Urban sensing using mobile phone network data: a survey of research," $A C M$ Computing Surveys, vol. 47, no. 2, article 25, pp. 25:1-25:20, 2015.

[108] K. Augustin, R. Gerike, M. J. Martinez Sanchez, and C. Ayala, "Analysis of intercity bus markets on long distances in an established and a young market: the example of the U.S. and Germany," Research in Transportation Economics, vol. 48, pp. 245-254, 2014, Competition and Ownership in Land Passenger Transport (selected papers from the Thredbo 13 conference).

[109] M. Delaplace and F. Dobruszkes, "From low-cost airlines to lowcost high-speed rail? the French case," Transport Policy, vol. 38, pp. 73-85, 2015.

[110] P. Chiambaretto and A.-S. Fernandez, "Transferring low-cost marketing practices from air to rail services: The Ouigo case," Research in Transportation Business and Management, vol. 10, pp. 40-44, 2014. 
[111] UIC, “Night trains 2.0—new opportunities by HSR?” International Union of Railways, 2013.

[112] EU, "Flightpath 2050 europes vision for aviation," European Commission, 2011.

[113] M. Zanin, "Can we neglect the multi-layer structure of functional networks?" Physica A: Statistical Mechanics and Its Applications, vol. 430, pp. 184-192, 2015.

[114] A. Cook, G. Tanner, S. Cristobal, and M. Zanin, "Delay propagation c new metrics, new insights," in Proceedings of the 11th USA/Europe Air Traffic Management Research and Development Seminar, 2015.

[115] C. Barnhart, D. Fearing, and V. Vaze, "Modeling passenger travel and delays in the national air transportation system," Operations Research, vol. 62, no. 3, pp. 580-601, 2014.

[116] A. Cook, G. Tanner, S. Cristóbal, and M. Zanin, "New perspectives for air transport performance," in Proceedings of the $3 \mathrm{rd}$ SESAR Innovation Days, November 2013.

[117] R. Henke, "Aeronautics research \& testing infrastructures," 2015.

[118] J. Haas and Y. Ban, "Urban growth and environmental impacts in Jing-Jin-Ji, the Yangtze, River Delta and the Pearl River Delta," International Journal of Applied Earth Observation and Geoinformation, vol. 30, no. 1, pp. 42-55, 2014.

[119] Y. Zhang and M. Hansen, "Real-time intermodal substitution: strategy for airline recovery from schedule perturbation and for mitigation of airport congestion," Transportation Research Record, vol. 2052, pp. 90-99, 2008.

[120] Y. Zhang and M. Hansen, "Real-time intermodal strategies for airline schedule perturbation recovery and airport congestion mitigation," in Proceedings of the INFORMS Annual Meeting, Charlotte, NC, USA, 2011.

[121] X. Sun, S. Wandelt, M. Hansen, and A. Li, "Multiple airport regions based on inter-airport temporal distances," Transportation Research Part E: Logistics and Transportation Review, vol. 101, pp. 84-98, 2017.

[122] S. V. Buldyrev, R. Parshani, G. Paul, H. E. Stanley, and S. Havlin, "Catastrophic cascade of failures in interdependent networks," Nature, vol. 464, no. 7291, pp. 1025-1028, 2010.

[123] M. Zanin and F. Lillo, "Modelling the air transport with complex networks: a short review," The European Physical Journal Special Topics, vol. 215, no. 1, pp. 5-21, 2013.

[124] S. Wandelt, X. Sun, and X. Cao, "Computationally efficient attack design for robustness analysis of air transportation networks," Transportmetrica A: Transport Science, vol. 11, no. 10, pp. 939-966, 2015.

[125] S. Wandelt, X. Sun, M. Zanin, and S. Havlin, "QRE: quick robustness estimation for large complex networks," Future Generation Computer Systems, 2017.

[126] X. Sun, V. Gollnick, and S. Wandelt, "Robustness analysis metrics for worldwide airport network: a comprehensive study," Chinese Journal of Aeronautics, vol. 30, no. 2, pp. 500-512, 2017.

[127] X. Sun, S. Wandelt, and F. Linke, “Temporal evolution analysis of the European air transportation system: air navigation route network and airport network," Transportmetrica B, vol. 3, no. 2, pp. 153-168, 2015.

[128] M. Dotoli, M. P. Fanti, A. M. Mangini, G. Stecco, and W. Ukovich, "The impact of ICT on intermodal transportation systems: a modelling approach by Petri nets," Control Engineering Practice, vol. 18, no. 8, pp. 893-903, 2010.

[129] S. Consolvo, P. Klasnja, D. W. McDonald et al., "Flowers or a robot army?: Encouraging awareness \&amp; activity with personal, mobile displays," in Proceedings of the 10th International
Conference on Ubiquitous Computing (UbiComp '08), pp. 54-63, New York, NY, USA, 2008.

[130] P. Nitsche, P. Widhalm, S. Breuss, N. Brändle, and P. Maurer, "Supporting large-scale travel surveys with smartphones - A practical approach," Transportation Research Part C: Emerging Technologies, vol. 43, pp. 212-221, 2014.

[131] A. Vij and K. Shankari, "When is big data big enough? Implications of using GPS-based surveys for travel demand analysis," Transportation Research Part C: Emerging Technologies, vol. 56, pp. 446-462, 2015.

[132] M. Mun, S. Reddy, K. Shilton et al., "PEIR, the personal environmental impact report, as a platform for participatory sensing systems research," in Proceedings of the 7th ACM International Conference on Mobile Systems, Applications, and Services (MobiSys '09), pp. 55-68, June 2009.

[133] R. Dekker, J. Bloemhof, and I. Mallidis, "Operations research for green logistics-an overview of aspects, issues, contributions and challenges," European Journal of Operational Research, vol. 219, no. 3, pp. 671-679, 2012. 


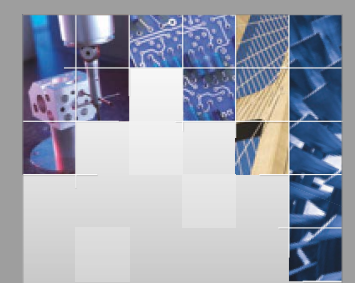

\section{Enfincering}
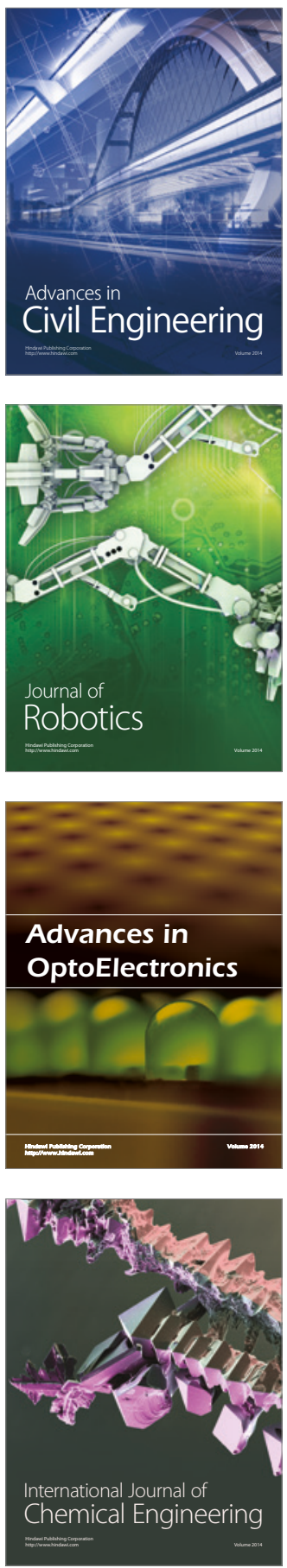

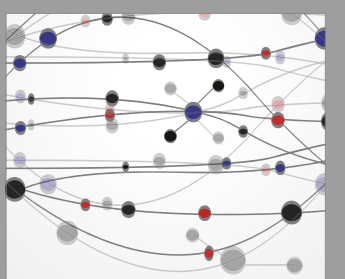

The Scientific World Journal

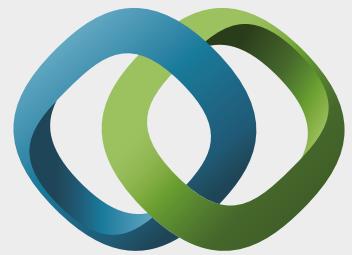

\section{Hindawi}

Submit your manuscripts at

https://www.hindawi.com
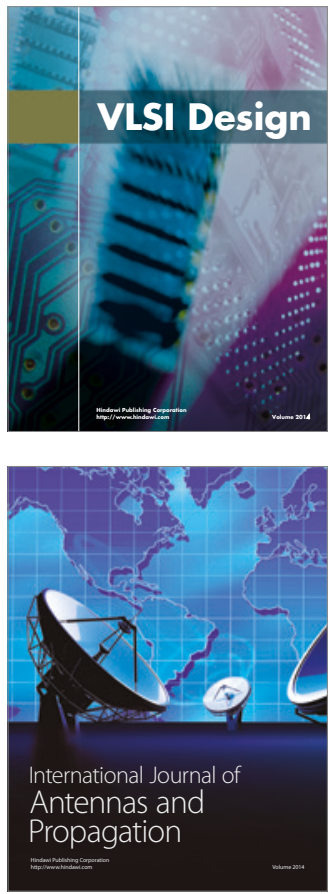

\section{Rotating}

Machinery
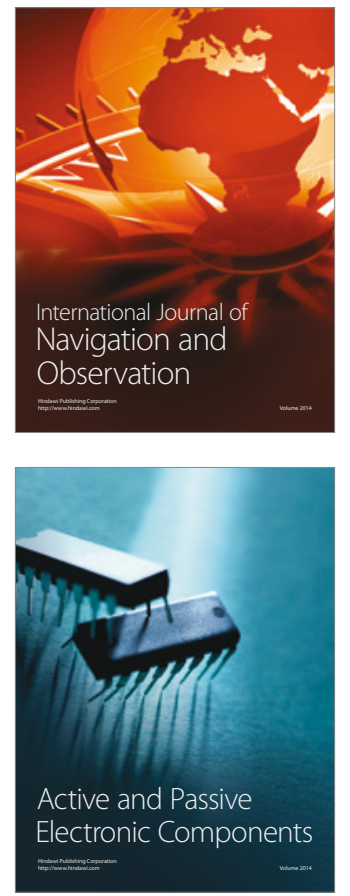
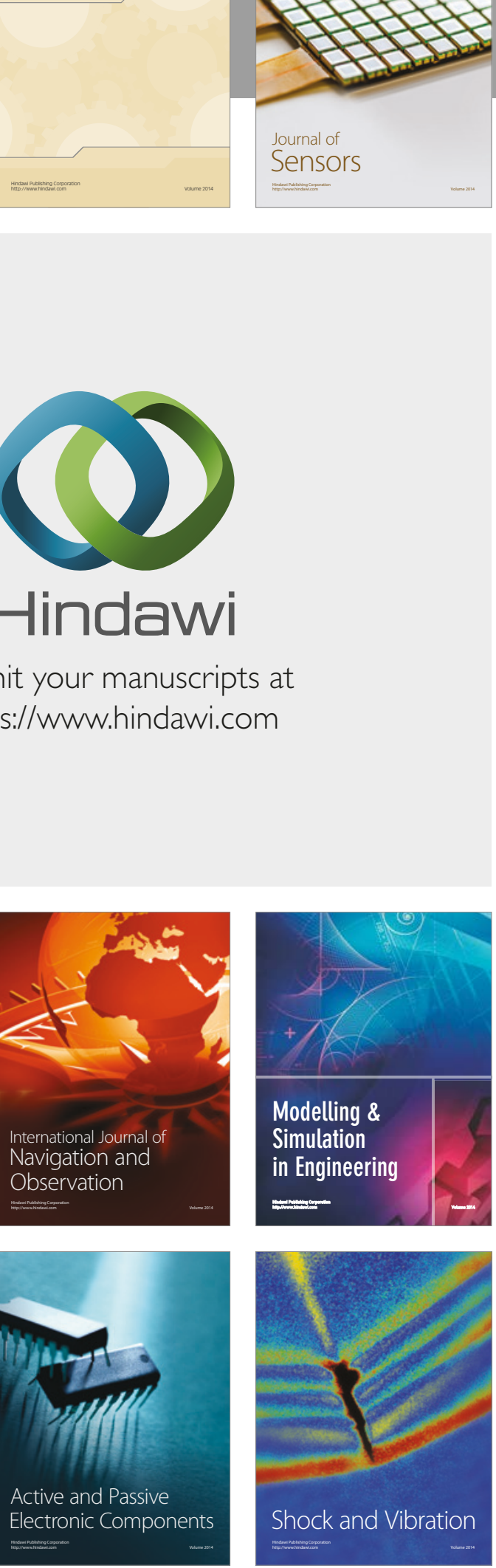
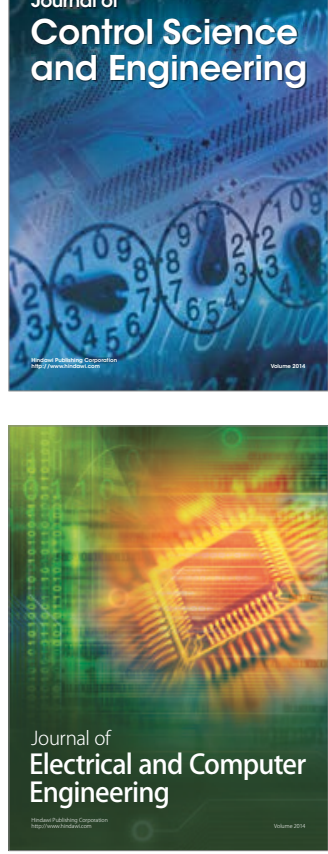

Distributed

Journal of

Control Science

and Engineering
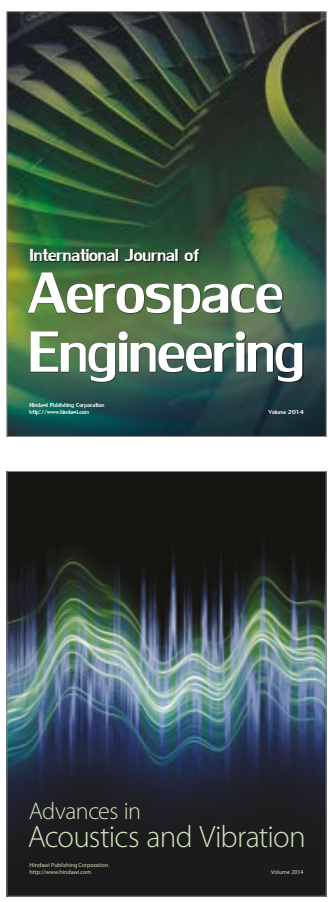

Sensor Networks 